\title{
OPTIMAL FINANCIAL CONTRACTS \\ With Hidden Effort, Unobservable Profits And Endogenous \\ COSTS OF EFFORT*
}

\author{
Viet Anh Dang \\ Manchester Business School \\ University of Manchester
}

\begin{abstract}
This paper studies financial contracting in a two-period financing model with double moral hazard, as entrepreneurial effort choices and profits are unobservable and nonverifiable. The optimal financial contract must induce both the high effort level and truthful revelation of profits. The paper further analyses the structure of the optimal contract where the entrepreneur's payoff takes a general functional form that allows for endogenously determined costs of effort. The entrepreneur's performance is influenced by not only extrinsic work motivation factors but also by intrinsic factors so that the degree of control imposed by the investor, in the form of end-of-period transfers, affects the entrepreneur's costs of effort. The finding shows that under welldefined conditions, the optimal contract that solves a model with non-verifiable profits also elicits effort, and generally resembles a simple debt contract. The structure of the optimal contract is robust in the general case where the entrepreneur's payoff function is non-linear in transfers.
\end{abstract}

JEL Classification: G82, G32.

Keywords: Debt contracts; moral hazard; unobservable profits; hidden effort; endogenous costs of effort.

\footnotetext{
* Viet Anh Dang, Manchester Business School, University of Manchester, Manchester M15 6PB, UK. Email address: Vietanh.Dang@mbs.ac.uk. I am grateful to Abimbola Adedeji, Dan Coffey, Robert Hudson, Kevin T. Reilly and Karl Shutes and participants at the Financial Management Association Annual Meeting 2006, and Manchester Business School Finance Seminar 2007 for their comments and suggestions on this paper. I would also like to thank two anonymous referees and an editor for their helpful comments and suggestions that greatly improve the paper. All remaining errors are my own.
} 


\section{Introduction}

The security design literature has studied the optimality of financial contracts in various principal-agent settings in which moral hazard exists because the agent's action or output is unobservable to the principal (see Allen and Winton, 1995). Two forms of moral hazard have been the focus of research in this area. The principalagent approach has generally examined (single-period) financing models in which, ex ante, the agent (the entrepreneur) exerts hidden effort after receiving financing from the principal (the investor), but before the state of nature is realised (e.g. Innes, 1990; Dewatripont et al., 2003). ${ }^{12}$ In this standard setup, cash flows are assumed to be observable (and verifiable) and the financial contract must induce the optimal effort choice. The finance approach has focused on models where entrepreneurial effort is observable but profits (cash flows) are unobservable and non-verifiable, thus leading to an ex post incentive problem (e.g. Bolton and Scharfstein, 1990; Hart and Moore, 1998). However, prior research has studied these ex ante and ex post moral hazard problems in isolation, and has not yet examined a more realistic setting in which both moral hazard problems are present and interact, i.e. effort is hidden and cash flows are unobservable and non-verifiable. Consequently, the features of the optimal financial contract that induces both effort and truthful revelation of profits remain unexplored.

In this paper, we aim to fill this gap in the literature by studying financial contracting in a two-period model with hidden entrepreneurial effort ex ante, and unobservable (non-verifiable) profits ex post. Under this hybrid framework, the

\footnotetext{
${ }^{1}$ For classical moral hazard models with hidden effort, see Mirrless (1999), Holmstrom, (1979) and Grossman and Hart (1983).

2 The models by Innes (1990) and Dewatripont et al. (2003) assume limited liability and monotonicity but do not allow for the possibility of refinancing. Matthews (2001) and Dewatripont et al. (2003) consider the possibility of renegotiating the contract after effort is exerted and show debt is optimal even when the entrepreneur is risk averse. For multi-period principal-agent models with ex ante unobservable effort, see Biais et al. (2004). For recent general principal-agent models in continuous time, see Sannikov (2006).
} 
conflict of interest between the entrepreneur and the investor has two dimensions as the former party may gain private benefit by exerting low effort and/or reporting profits untruthfully. ${ }^{3}$ The optimal financial contract that specifies end-of-period transfers to the investor and the probabilities of refinancing the firm (in the second period) must induce not only truthful reporting of profits but also the high level of effort. An important aspect of this contracting environment is potential interactions between the two moral hazard problems as the features of the optimal contract affect the entrepreneur's effort level chosen ex ante, which in turn affects the distribution of profits ex post. On the other hand, ex post, the non-verifiability of profits may affect the ability to design a credible effort incentive scheme ex ante. It may not be possible for the entrepreneur to signal "working" when he/she reports a low profit, which the investor may view as potential concealment. The optimal contract, for example, may not be able to induce effort in the second period where the entrepreneur has no incentive to report (non-verifiable) profits truthfully.

A second important contribution of the paper is the characterisation of the optimal financial contract when the entrepreneur's payoff takes a general functional form as costs of effort are endogenously determined. Following recent research in the industrial-organisation literature (Frey, 1997; Murdock, 2002; Benabou and Tirole, 2003), we consider a principal-agent framework in which the entrepreneur's productivity and utility are affected intrinsically by a number of factors within the working environment. Specifically, the entrepreneur's performance is not only determined by extrinsic work motivation factors in the form of pecuniary pay and rewards, but also by intrinsic factors (e.g. the level of being controlled), and the

\footnotetext{
${ }^{3}$ The entrepreneur can exert the optimal effort level (e.g. "working") but, ex post, report profits untruthfully and divert cash flows for private consumption. Similarly, the entrepreneur who "shirks" can report profits either truthfully or untruthfully to conceal his/her action.
} 
interaction between them (see Willner, 1999 for an illustration). Our model assumes that the degree of control imposed by the investor, in the form of end-of-period transfers, affects the entrepreneur's evaluation of utility and costs of effort. This complicates the contracting problem because the higher the transfers to the investor, the more committed he/she is to refinancing the firm but also the higher entrepreneurial effort costs and the more likely the entrepreneur "shirks". The paper is the first to deal with this endogeneity issue explicitly by formulating the entrepreneur's payoff as a non-linear function of transfers to the investor.

We find that under well-defined conditions, an incentive mechanism that ensures truthful reporting of profits can effectively elicit the high level of effort. This finding suggests that the optimal contract that solves a model with a moral hazard problem due to unobservable (non-verifiable) profits also solves a more general model with an additional moral hazard problem due to hidden effort. Further, the optimal contract generally bears resemblance to a debt contract: when the entrepreneur reports a low profit, he/she will transfer all the profit to the investor and face liquidation. Reporting a low profit cannot signal that the entrepreneur exerts high effort and/or reports profits truthfully. The liquidation threat is a credible and efficient disciplining device whereby the investor always withholds future financing when there is a possibility that the entrepreneur "shirks" and/or conceals true profits. The entrepreneur will only receive second-round financing only when he/she reports a high-profit outcome. The debt-like feature of the optimal contract is generally robust to an extended setting in which the entrepreneur's payoff function is non-linear in transfers to the investor.

Overall, our debt optimality finding is consistent with the results of existing financing models with unobservable (non-verifiable) profits. A debt-like contract 
typically emerges as optimal in this setting because it can credibly enforce repayment and deter cash flow diversion by imposing non-pecuniary penalties on the entrepreneur (Diamond, 1984), by threatening to withhold second-period financing (Bolton and Scharfstein, 1990; Faure-Grimaud, 2000; Povel and Raith, 2004), or by seizing and liquidating existing physical assets (Hart and Moore, 1989, 1998). ${ }^{4}$ Our results corroborate the previous literature in demonstrating the importance of a debt contract in situations with double moral hazard and non-linearity and showing why it is a widely used financial instrument in practice (see Tirole, 2006).

The paper is related to a growing literature that has begun to consider multiple agency problems in a unified framework. Dionne and Viala (1994) characterise the optimal contract when there is double moral hazard due to unobservable profits and unobservable action. Unlike our setting, however, their model follows the costly state verification literature that assumes privately observed cash flows can be verified with a finite audit cost (e.g. Townsend, 1979; Gale and Hellwig, 1985). Lawarree and Audenrode (1996) consider a financing model with hidden effort and unobservable output but make a different assumption that the agent exerts effort ex post after observing the state of nature privately (i.e. adverse selection). ${ }^{5}$

Finally, this paper is closely related to a number of recent models with multifaceted moral hazard. Povel and Raith (2004) consider a financing model in which investment decisions and the resulting profits are non-contractible. DeMarzo and Fishman (2007a) incorporate contractible investment into a multi-period agency

\footnotetext{
${ }^{4}$ Fluck (1998), Myers (2000) and Dybvig and Wang (2002) show that outside equity may be optimal and dominate debt contracts in several contracting settings with non-verifiable cash flows. de Bettignies (2008) studies venture capital financing and shows that various forms of financial contracts used in the real world such as debt, equity and convertible securities can also emerge as optimal.

${ }^{5}$ See also an earlier study by Laffont and Tirole (1986) that examines a procurement contract between a planner and a firm under both moral hazard (unobservable effort) and adverse selection (unobservable efficiency) in the context of regulation.
} 
model with privately observed cash flows or hidden effort and examine the implied investment dynamics. DeMarzo and Sannikov (2006) and DeMarzo and Fishman (2007b) characterise the optimal long-term financial contract, in the presence of moral hazard due to unobservable cash flow, and/or hidden effort in discrete and continuous time, respectively. ${ }^{6}$ Our study complements these models in that we further examine the robustness of the optimal debt finding to a more realistic setting by rendering the entrepreneur's payoff non-linear via endogenously determined costs of effort.

The remainder of this paper is organised as follows. For ease of exposition, section 2 develops a two-period model with hidden effort (but with observable and verifiable profits), and then characterises the optimal contract that elicits the "firstbest" effort in both periods. Section 3 examines the optimality of the financial contract in the presence of two-dimensional moral hazard with hidden effort and unobservable (non-verifiable) profits. Section 4 considers an extended setting in which the entrepreneur's payoff is a non-linear function as the cost of effort is partly affected by the size of transfers. Section 5 concludes.

\section{Financial Contracts With Hidden Effort}

In this section, we consider a firm with a risk-neutral entrepreneur/manager, operating over two periods. It is assumed that ex post, profits are observable and verifiable, but ex ante, entrepreneurial effort choices are not. The sequence of the model is as follows. At the beginning of each period, a risk-neutral investor makes a take-it-orleave-it offer to the entrepreneur, who has no internal funds and must borrow an amount, $F$, to finance an investment project. $^{7}$ After receiving funds, ex ante, the

\footnotetext{
${ }^{6}$ Williams (2005) also studies a dynamic and continuous-time setting assuming both hidden actions and possibly hidden states. His model, however, is a general principal-agent setup and does not assume limited liability.

${ }^{7} \mathrm{We}$ assume the investment is taken as given and it is impossible for the entrepreneur to divert the funds to other projects. See Povel and Raith (2004) for a model with unobservable investments.
} 
entrepreneur privately chooses between a high and low effort level. ${ }^{8}$ After the state of nature is realised, the entrepreneur reports true profits to the investor. We model profits as a discrete random variable, with $\pi_{H}$ and $\pi_{L}$ representing the high and low profit level, respectively (i.e. $\pi_{H}>\pi_{L} \geq 0$ ). ${ }^{9}$ Further, assume the investment project generates a loss in a low-profit outcome, i.e. $\pi_{L}<F .^{10}$

Let $\theta_{W}$ and $\theta_{S}(\in(0,1))$ be the probabilities that the profit is low $\left(\pi_{L}\right)$, conditional on high and low effort exerted, respectively. We follow Innes (1990) and assume that $\theta_{S} \geq \theta_{W}$, implying better profit distributions are non-decreasing in the levels of effort exerted in the sense of the strict Monotone Likelihood Ratio Property (hereafter MLRP). ${ }^{11}$ Assume that the probabilities $\theta_{W}$ and $\theta_{S}$ are common knowledge with the conditional expected profit in each period given by $\bar{\pi}_{W}$ or $\bar{\pi}_{S}$, where $\bar{\pi}_{W}=\theta_{W} \pi_{L}+\left(1-\theta_{W}\right) \pi_{H}$ and $\bar{\pi}_{S}=\theta_{S} \pi_{L}+\left(1-\theta_{S}\right) \pi_{H}$. Notice that $\bar{\pi}_{W} \geq \bar{\pi}_{S}$ by the condition $\theta_{S} \geq \theta_{W}$. We further assume that the Net Present Value (hereafter NPV) of the investment is non-negative when high effort is exerted, $\bar{\pi}_{W} \geq F$; hence the inequality $\pi_{H}>\bar{\pi}_{W} \geq F>\pi_{L}$.

At the end of the first period, conditional on the low (high) profit being reported, the entrepreneur makes a positive transfer $R_{L}\left(R_{H}\right)$ to the investor, who refinances the firm's second-period investment with probability $\beta_{L}\left(\beta_{H}\right)$, with $\beta_{L}, \beta_{H} \in[0,1]$. Assume that at least one refinancing probability is not equal to zero,

\footnotetext{
${ }^{8}$ This binary setting can be viewed as one in which the entrepreneur chooses to either "work" or "shirk".

${ }^{9}$ See Bolton and Scharfstein (1990) and Snyder (1996) for a similar setting with discrete profits. See Faure-Grimaud (2000) and Povel and Raith (2004) for models with continuous profits.

${ }^{10}$ Tchistyi (2005) considers a dynamic model in which unobservable cash flows are correlated overtime.

${ }^{11}$ The MLRP requires that higher effort levels will result in higher profit distributions, or formally, $\theta_{S} / \theta_{W} \geq\left(1-\theta_{S}\right) /\left(1-\theta_{W}\right)$ (see Rogerson, 1985).
} 
and that $\beta_{L} \leq \beta_{H}$, implying the investor designs a contract that makes it costly for the entrepreneur who "shirks" and makes a low profit. ${ }^{12}$

If the project is not refinanced, the contract terminates; if it receives secondround financing, the above sequence repeats in the second period. ${ }^{13}$ For simplicity, we follow Bolton and Scharfstein (1990) and do not consider the possibility of renegotiating the contract. ${ }^{14}$ At the end of the second period, the entrepreneur makes a positive transfer $R^{L}\left(R^{H}\right)$ to the investor corresponding to the low (high) level of profit reported. Assume that the discount rate is equal to zero so that the firm's expected profit in the second period remains to be $\bar{\pi}_{W}$ or $\bar{\pi}_{S}$. Finally, denote $\bar{R}_{W}$ and $\bar{R}_{S}$ as the expected second-period transfers, where $\bar{R}_{W}=\theta_{W} R^{L}+\left(1-\theta_{W}\right) R^{H}$ and $\bar{R}_{S}=\theta_{S} R^{L}+\left(1-\theta_{S}\right) R^{H}$, respectively.

The investor's utility function is the sum of the expected transfers over the two periods less the initial fund, $F$, borrowed at the beginning of each period. The entrepreneur's utility function is the residual cash flows after transfers less the cost of effort. ${ }^{15}$ We denote $c_{W}$ and $c_{S}$ as the cost of high and low effort, respectively and assume $c_{W}>c_{S} \geq 0$, implying the higher effort level, the higher the cost of effort. ${ }^{16}$

\footnotetext{
${ }^{12}$ To ensure that the firm is always cash-constrained and requires second-round finance, we assume that any residual cash flows after transfers in the first period cannot be used to partially fund the investment in the second period.

${ }^{13}$ See Faure-Grimaud and Mariotti (1999) for models in which continuation value is positively related to first-period profits.

${ }^{14}$ Renegotiation in the context of financing models is an interesting but complicated research question, which is beyond the scope of this paper. See, for example, Snyder (1996) for an extension of the Bolton and Scharfstein model that considers the implication of renegotiation for predation. See also Matthews (2001) and Dewatripont et al. (2003), who subsequently extend Innes (1990) and examine the optimality of the debt contract in the presence of renegotiation.

${ }^{15} \mathrm{It}$ is assumed that the cost of effort is independent of transfers (i.e. $\partial c / \partial R=0$ ). In section 4, we consider the case in which the cost of effort is a general function in transfers.

${ }^{16}$ In our analysis, without loss of generality, we normalise the cost of effort by setting $c_{S}=0$ (the effort cost is zero when the entrepreneur "shirks") and replace the expression $\left(c_{W}-c_{S}\right)$ everywhere with $c_{W}$.
} 
We define the term financial contract as follows. A contract is an agreement specifying a triple of variables $\left\{\beta_{i}, R_{i}, R^{i}\right\}$ (where $i=L, H$ ), namely second-period refinancing probabilities, first-period transfers and second-period transfers, respectively. A feasible contract refers to any one contract that satisfies all the conditions of the model. An optimal contract is any feasible contract that maximises the objective function of the investor who makes the offer. Throughout the paper, the modifier "first-best" denotes outcomes or equilibrium contracts that induce the entrepreneur to exert the high level of effort and maximise the investor's objective function.

The maximisation programme is

Programme (A)

Maximise $f\left(\beta_{i}, R_{i}, R^{i}\right)=\theta_{W}\left(R_{L}+\beta_{L}\left(\bar{R}_{W}-F\right)\right)+\left(1-\theta_{W}\right)\left(R_{H}+\beta_{H}\left(\bar{R}_{W}-F\right)\right)-F$

subject to

$\theta_{W}\left[\pi_{L}-R_{L}-c_{W}+\beta_{L}\left(\bar{\pi}_{W}-\bar{R}_{W}-c_{W}\right)\right]+\left(1-\theta_{W}\right)\left[\pi_{H}-R_{H}-c_{W}+\beta_{H}\left(\bar{\pi}_{W}-\bar{R}_{W}-c_{W}\right)\right]$

$\geq \theta_{j}\left[\pi_{L}-R_{L}-c_{j}+\beta_{L}\left(\bar{\pi}_{k}-\bar{R}_{k}-c_{k}\right)\right]+\left(1-\theta_{j}\right)\left[\pi_{H}-R_{H}-c_{j}+\beta_{H}\left(\bar{\pi}_{k}-\bar{R}_{k}-c_{k}\right)\right]$

where $k=S$ when $j=W ; k=W$ or $S$ when $j=S$.

$\pi_{i} \geq R_{i}$, where $i=L, H$.

$\pi_{i} \geq R^{i}$, where $i=L, H$.

$\theta_{S}\left[\pi_{L}-R_{L}-c_{S}+\beta_{L}\left(\bar{\pi}_{S}-\bar{R}_{S}-c_{S}\right)\right]+\left(1-\theta_{S}\right)\left[\pi_{H}-R_{H}-c_{S}+\beta_{H}\left(\bar{\pi}_{S}-\bar{R}_{S}-c_{S}\right)\right] \geq 0$

The optimal contract must incentivise the entrepreneur to exert high effort in both periods. Condition (2) is an incentive compatibility constraint (hereafter IC) that induces the entrepreneur to choose high effort. Conditions (3) and (4) are two limited liability (hereafter LL) constraints that ensure transfers made to the investor do not 
exceed end-of-period profits. ${ }^{17}$ Condition (5) is a standard individual rationality constraint (hereafter IR) that guarantees the entrepreneur's expected payoff is nonnegative.

In order to solve this problem and characterise the optimal contract, we first analyse the IC constraint (2) and summarise the results in the following lemma. ${ }^{18}$

Lemma 1. The incentive compatibility constraint in (2) is the combination of the following two conditions:

$$
\begin{aligned}
& \pi_{L}-R^{L} \leq \pi_{H}-R^{H}-c_{W} /\left(\theta_{S}-\theta_{W}\right) \\
& \pi_{L}-R_{L} \leq \pi_{H}-R_{H}-c_{W} /\left(\theta_{S}-\theta_{W}\right)+\left(\beta_{H}-\beta_{L}\right)\left(\bar{\pi}_{W}-\bar{R}_{W}-c_{W}\right)
\end{aligned}
$$

Proof. See Appendix 1.

Condition (6) induces the high effort level in the second period by ensuring that the entrepreneur's payoff (i.e. second-period retained earning after the transfer made to the investor) is higher in a high-profit outcome than in a low-profit one. ${ }^{19}$ The incentivising tool that the investor employs involves making the payment to the entrepreneur contingent on the realised profit. This standard incentive mechanism is made possible because under the assumption of our model, high (low) effort exerted ex ante leads to a higher (lower) likelihood of realising high (low) profits ex post, consistent with the MLRP. The entrepreneur is induced to choose the high level of effort that increases the probability of higher profits and subsequently higher payments.

\footnotetext{
${ }^{17}$ The introduction of limited liability into financing models is due to Sappington (1983) and Innes (1990). Our financial contracting framework differs importantly from these earlier models in that we consider a two-period setting in which the entrepreneur (agent) can receive second-round financing but also face a potential liquidation threat, which, as we show, becomes an important feature of the optimal incentive scheme.

${ }^{18}$ Intuitively, there exists a class of feasible contracts subject to the constraints of the model with payments made contingent on the realised profit, but not on the period. We show, however, that such feasible contracts may not emerge as optimal, especially when effort is relatively costly.

${ }^{19}$ The expression, $c_{W} /\left(\theta_{S}-\theta_{W}\right)$, can be interpreted as the marginal cost of effort that the entrepreneur incurs to increase the probability of high profits.
} 
Condition (7) is an incentive mechanism that deters "shirking" in the first period. As in (6), the investor is able to incentivise the entrepreneur to "work" by making the latter party's payoff contingent on the realised profit. There is, however, an additional incentivising tool available because in our two-period model, the investor can assign appropriate profit-contingent refinancing probabilities, and, moreover, withhold second-period funds to discipline the entrepreneur who "shirks" and generates low first-period profits. Technically, this incentivising tool is represented by the expression $\left(\beta_{H}-\beta_{L}\right)\left(\bar{\pi}_{W}-\bar{R}_{W}-c_{W}\right)$, which is the entrepreneur's expected payoff multiplied by the difference in profit-contingent refinancing probabilities. $^{20}$

In light of Lemma 1, we solve programme (A) and report the main results in the following proposition.

Proposition 1. Let $m=\bar{\pi}_{W}-F-c_{W}$ and $n=\left(1-\theta_{S}\right) c_{W} /\left(\theta_{S}-\theta_{W}\right)$, the investor finances the firm if and only if $m \geq 0$ and $\left(2-\theta_{W}\right) m \geq n$. If $\theta_{W} m-n \geq 0$, the optimal contract specifies:

Contract (FC1): $\beta_{L}=1, \beta_{H}=1, R_{L}=R^{L}=\pi_{L}, R_{H}=R^{H}=\pi_{H}-c_{W} /\left(\theta_{S}-\theta_{W}\right)$

If $\left(2-\theta_{W}\right) m \geq n>\theta_{W} m$, the optimal contract specifies:

Contract (FC2): $\beta_{L}=0, \beta_{H}=1, R_{L}=\pi_{L}$, $R_{H}=\pi_{H}+\left[(s-1)-[(s-1)-t] \theta_{W}-\theta_{S}\right] c_{W} /\left(\theta_{S}-\theta_{W}\right), R^{H}=\pi_{H}-s \times c_{W} /\left(\theta_{S}-\theta_{W}\right)$, where $s, t \in R_{+}$such that $s \geq 1,0 \leq t \leq s-1, t<1$ and $(s-1)-[(s-1)-t] \theta_{W}-\theta_{S} \leq 0$.

Proof. Appendix 2.

\footnotetext{
${ }^{20}$ This incentivising tool becomes irrelevant, however, if the refinancing probabilities are set equal, i.e. $\beta_{L}=\beta_{H}$, regardless of the realised profit. For example, if the investor promises to refinance the firm with certainty (i.e. $\beta_{L}=\beta_{H}=1$ ) then the incentive mechanisms in conditions (6) and (7) are effectively identical, i.e. the investor induces the high effort level in both periods by designing profit-contingent payoffs.
} 
Proposition 1 shows that the feasibility and optimality of the contract depends on the relative sizes of an expression of the cost of effort, $n=\left(1-\theta_{S}\right)\left(c_{W}\right) /\left(\theta_{S}-\theta_{W}\right)$, and that of the expected NPV of the investment, $m=\bar{\pi}_{W}-F-c_{W}$. In an extreme case where the marginal cost of effort is relatively too high as compared to the expected NPV, such that $m\left(2-\theta_{W}\right)<n$, then no feasible contracts will exist. The intuition behind this result is simple: in order to offset the high marginal cost of effort, the "working" entrepreneur would have to be compensated with a large share of the firm's earnings, making it unprofitable for the investor to enter into a contract and provide the capital. If, on the other hand, exerting high effort is relatively less costly as compared to the expected NPV, such that $\left(2-\theta_{W}\right) m \geq n$, then the optimal financial contract takes the form of either (FC1) or (FC2).

Contracts (FC1) and (FC2) differ in a number of aspects, the most important of which lies in the way in which the refinancing probabilities are designed. Specifically, in (FC1), the refinancing probabilities are both set equal to 1, indicating that the entrepreneur will receive second-round funds with certainty, regardless of the first-period profit (i.e., $\beta_{L}=\beta_{H}=1$ ). In (FC2), however, the refinancing probabilities are made contingent on the first-period profit such that the firm will face liquidation in a low-profit outcome but receive second-round financing in a high profit realisation (i.e., $\beta_{L}=0$ and $\beta_{H}=1$ ). As demonstrated by Lemma 1 , in order to induce the high effort level in the first period, the investor can utilise two incentivising tools, including profit-contingent payments to the entrepreneur, and the probability of continued financing of the project in the second period. Proposition 1 shows that only 
the first incentivising tool is employed in Contract (FC1), whereas both tools are combined and used together in Contract (FC2). ${ }^{21}$

To study the reasons for the different design of the incentive schemes in (FC1) and (FC2), we next turn to analyse the benefits and costs of the two incentivising tools available at the disposal of the investor, i.e. profit-contingent payments and refinancing probabilities. The first incentivising tool, as used in (FC1), is a standard mechanism in the financial contracting literature and capable of eliciting effort (see, for example, Sappington, 1983; Innes, 1990). Under this incentive mechanism, the payments made to the entrepreneur (agent) are typically non-decreasing in firm profits (output), hence providing the entrepreneur incentives to exert high effort that increases the probability of high profits. In our two-period game, however, the efficiency of this incentivising tool is reduced because absent a strong disciplining device, it is more difficult and costly to elicit the first-period effort. In particular, the entrepreneur can choose to "shirk" in the first period but will still be entitled to a payoff in the second period as the firm is refinanced with certainty. To induce the high level of first-period effort, the investor must increase the entrepreneur's payoff differential between a high- and a low-profit outcome, thereby compensating the differential cost of effort plus the expected second-period payments. Technically, Proposition 1 shows that only when $\theta_{W} m \geq n$ (i.e. the marginal cost of effort is relatively low as compared to the project's NPV) will (FC1) remain as the optimal contract.

It follows from the above analysis that when the marginal cost of effort is relatively high, such that $\left(2-\theta_{W}\right) m \geq n>\theta_{W} m$, the incentive scheme based on profit-

\footnotetext{
${ }^{21}$ In Contract (FC1), the investor could, in principle, use the liquidation threat (i.e. $\beta_{L}=0$ and $\beta_{H}=1$ ) in combination with profit-contingent payments as in (FC2); however, that design would make the contract suboptimal as it would not maximise the investor's objective function. See Appendix 2.
} 
contingent payments used in (FC1) becomes less efficient. While Contract (FC1) remains to be a feasible contract, it does not maximise the investor's objective function. In this case, a more credible and efficient disciplining device is required: in the optimal contract (FC2), the termination threat becomes an important feature because it increases the cost of "shirking", thereby inducing greater effort at a lower cost. More specifically, under this incentive scheme, a low level of effort exerted in the first period increases the probability of a low-profit realisation and subsequent liquidation. The use of a termination threat as the maximum punishment is shown to be an important characteristic of financial contracting in multi-period settings (e.g. Bolton and Scharfstein, 1990), and one that renders Contract (FC2) analogous to a simple debt contract. However, this disciplining device has potential disadvantages and costs. Although effort and profit distributions are related in the sense of the MLRP, it is possible that a low (high) profit is simply due to bad (good) luck and not necessarily due to low (high) effort exerted. The entrepreneur, for example, may still face potential liquidation even when choosing the high effort level. More importantly, unlike Contract (FC1), (FC2) is economically inefficient because ex post the investor may refuse second-round financing even when the investment project has nonnegative NPV.

In terms of the transfers to the investor, there are similarities between (FC1) and (FC2). Both contracts specify that in a low-profit outcome, all the profit will be transferred to the investor, thereby making the entrepreneur's residual payoff equal to zero $\left(R_{L}=R^{L}=\pi_{L}\right.$ in $\mathrm{FC}(1)$ and $R_{L}=\pi_{L}$ in (FC2)). As in standard effort-elicitation models (e.g. Innes, 1990), the investor typically disciplines the entrepreneur by extracting the entire profit in a low-profit outcome. Note that this feature, used in combination with the termination threat, makes Contract (FC2) similar to a debt 
contract. Finally, only when a high profit level is realised, will the entrepreneur be able to retain part of the profit (i.e. $R_{H}=R^{H}<\pi_{H}$ ). In Contract (FC1), for example, the entrepreneur will receive a payoff exactly equal to the marginal cost of effort.

Unlike (FC1), Contract (FC2) is not unique but a set of optimal contracts. The transfers made to the investor in Contract (FC2) are contingent on the stage of the game and dependent on the values of the parameters $\left\{\theta_{W}, \theta_{S}, s, t\right\}$. Notice that the effort IC constraint (6) is only binding when the parameters of Contract (FC2) satisfy the condition $s-t=1$. For the purpose of illustration, when $s=1$ and $t=0$, Contract (FC2a) emerges as a special case of (FC2) with $\left\{\beta_{L}=0, \beta_{H}=1, R_{L}=\pi_{L}\right.$, $\left.R_{H}=\pi_{H}-\theta_{S} \times c_{W} /\left(\theta_{S}-\theta_{W}\right), R^{H}=\pi_{H}-c_{W} /\left(\theta_{S}-\theta_{W}\right)\right\}$. The features of Contract (FC2a) only differ from those of Contract (FC1) in two aspects: (FC2a) specifies $\beta_{L}=0$ and $R_{H}=\pi_{H}-\theta_{S} \times c_{W} /\left(\theta_{S}-\theta_{W}\right)$, while in Contract (FC1), $\beta_{L}=1$ and $R_{H}=\pi_{H}-c_{W} /\left(\theta_{S}-\theta_{W}\right)$. Despite incurring a relatively higher cost of effort, the entrepreneur entering into Contract (FC2a) is required to make a higher first-period transfer to the investor to avoid facing liquidation and ensure continued financial support. Importantly, unlike (FC1), Contract (FC2a) (and (FC2) in general) features the liquidation threat $\left(\beta_{L}=0\right)$ as a unique characteristic of a debt contract.

Finally, for completeness, we briefly consider a class of suboptimal contracts that only induce the high level of effort in one period and compare them to the equilibrium contracts in (FC1) and (FC2). When the investor incentivises the high effort in the second period but not in the first period, (7) will be relaxed and dropped from the maximisation programme. Thus, as in Contract (FC1), the termination threat will not be included in the incentive mechanism. Unlike in (FC1), however, the investor will extract all the first-period profit because the entrepreneur will "shirk" 
and there is no need for the former party to provide an incentive scheme that rewards high effort. The IC constraint (6) binds and the sub-optimal contract would specify $\left\{R_{L}=\pi_{L}, R_{H}=\pi_{H}, R^{L}=\pi_{L}, R^{H}=\pi_{H}-c_{W} /\left(\theta_{S}-\theta_{W}\right)\right\} ;$ the firm will then be refinanced with certainty with $\beta_{L}=1$ and $\beta_{H}=1$ (see case II in Appendix 2 for more detail). Similarly, when the contract only induces the high effort level in the first period but not in the second period, the IC constraint (6) will be relaxed while (7) will be binding. Following the above argument, the investor has an incentive to extract all the profit generated in the second period. The sub-optimal financial contract would specify $\left\{R_{L}=\pi_{L}, R_{H}=\pi_{H}-c_{W} /\left(\theta_{S}-\theta_{W}\right), R^{L}=\pi_{L}, R^{H}=\pi_{H}\right\}$ with $\beta_{L}=1$ and $\beta_{H}=1$. This suboptimal contract does not feature a termination threat but uses profitcontingent payments as the only incentivising tool.

\section{Financial Contracts With Hidden Effort and Unobservable Profits}

The model developed in Section 2 assumes that effort choices are hidden but profits are observable and verifiable. In this section, we relax this assumption and extend the contracting framework by considering an additional incentive problem in which ex post profits are privately observable to the entrepreneur and cannot be verified. ${ }^{22} \mathrm{We}$ assume that while profits are non-verifiable, the low profit level, $\pi_{L}$, is common knowledge and can be extracted from the firm. It is, thus, equivalent to assuming that $\pi_{L}$ is the verifiable component and the profit differential, $\pi_{H}-\pi_{L}$, is the nonverifiable one (Bolton and Scharfstein, 1990). Under this assumption, the entrepreneur can under-report profits in a high-profit outcome and divert the residual cash flows, $\pi_{H}-\pi_{L}$, for his/her private consumption. To ensure that untruthful

\footnotetext{
${ }^{22}$ It is also possible to assume that profits are observable to both the entrepreneur and investor, but not verifiable and contractible, i.e. they cannot be verified by the court. The intuition behind this assumption is that due to various creative accounting techniques available, entrepreneurs/managers have some discrete in reporting profits, hence the ability to divert pecuniary benefits.
} 
revelation of profits is possible, we maintain the LL constraint. Further, we follow Innes (1990) and assume that the transfer to the investor is non-decreasing in firm profits (i.e. monotonic contract). ${ }^{23}$ Finally, assume that the firm will be liquidated if the investor refuses to refinance the investment project. ${ }^{24}$

The setting is analogous to the model analysed in section 2, except that in the second period, the transfers to the investor, denoted $R^{L}\left(R^{H}\right)$, cannot be made contingent on the second-period profit, but on the low (high) profit level announced in the first period. The level of second-period profits becomes irrelevant because the entrepreneur always conceals the true profit at this stage.

The optimal financial contract maximises the investor's expected payoff function, conditional on the entrepreneur exerting high effort in both periods, as well as reporting profits truthfully in the first period.

Programme (B)

Maximise $f\left(\beta_{i}, R_{i}, R^{i}\right)=-F+\theta_{W}\left(R_{L}+\beta_{L}\left(R^{L}-F\right)\right)+\left(1-\theta_{W}\right)\left(R_{H}+\beta_{H}\left(R^{H}-F\right)\right)$

subject to

$\theta_{W}\left[\pi_{L}-R_{L}-c_{W}+\beta_{L}\left(\bar{\pi}_{W}-R^{L}-c_{W}\right)\right]+\left(1-\theta_{W}\right)\left[\pi_{H}-R_{H}-c_{W}+\beta_{H}\left(\bar{\pi}_{W}-R^{H}-c_{W}\right)\right]$

$\geq \theta_{j}\left[\pi_{L}-R_{L}-c_{j}+\beta_{L}\left(\bar{\pi}_{k}-R^{L}-c_{k}\right)\right]+\left(1-\theta_{j}\right)\left[\pi_{H}-R_{H}-c_{j}+\beta_{H}\left(\bar{\pi}_{k}-R^{H}-c_{k}\right)\right]$

where $k=S$ if $j=W, \mathrm{k}=W, S$ if $j=S$.

$\pi_{H}-R_{H}-c_{W}+\beta_{H}\left(\bar{\pi}_{W}-R^{H}-c_{W}\right) \geq \pi_{H}-R_{L}-c_{W}+\beta_{L}\left(\bar{\pi}_{W}-R^{L}-c_{W}\right)$

$\pi_{i} \geq R_{i}$, where $i=L, H$.

$\pi_{i}-R_{i}+\pi_{L} \geq R^{i}$, where $i=L, H$.

\footnotetext{
${ }^{23}$ The monotonicity constraint rules out a possibility that transfers in a low-profit state could be set higher than in a high-profit one and so guarantees that the investor is unable to prevent concealment of profits by asking the entrepreneur to make transfers higher than the profits announced.

${ }^{24}$ Following Snyder (1996), it is assumed that if profits were under-reported, the amount of profit in excess of a low profit level could not be reinvested in the second period.
} 
$\theta_{S}\left[\pi_{L}-R_{L}-c_{S}+\beta_{L}\left(\bar{\pi}_{S}-R^{L}-c_{S}\right)\right]+\left(1-\theta_{S}\right)\left[\pi_{H}-R_{H}-c_{S}+\beta_{H}\left(\bar{\pi}_{S}-R^{H}-c_{S}\right)\right] \geq 0$

Condition (9) is an IC constraint that induces the entrepreneur to choose the high level of effort in both periods. Condition (10) is a standard direct revelation mechanism that ensures truthful revelation of profits; it guarantees that when the firstperiod profit level is high, the entrepreneur does not report that it is low. ${ }^{25}$ Conditions (11) and (12) are the two LL constraints. Notice that constraint (12) differs slightly from the LL constraint in programme (A) in that the size of second-period transfers, $R^{i}(i=L, H)$ does not exceed the residual cash flow from the first period, $\left(\pi_{i}-R_{i}\right)$, plus the low profit level, $\pi_{L} \cdot{ }^{26}$ Intuitively, the investor has an incentive to extract more first-period profits considering the entrepreneur always conceals and reports a low profit at the end of the second period. Finally, condition (13) is the usual IR constraint that ensures the entrepreneur's expected payoff is non-negative.

As with programme (A), we will solve programme (B) by first analysing the IC constraints of model. Our results are presented in Lemmas 2 and 3 as follows.

Lemma 2. The IC constraint (9) can be simplified to the following conditions:

$$
\begin{aligned}
& \pi_{L} \leq \pi_{H}-c_{W} /\left(\theta_{S}-\theta_{W}\right) \\
& \pi_{L}-R_{L}+\beta_{L}\left(\bar{\pi}_{W}-R^{L}-c_{W}\right) \leq \pi_{H}-R_{H}+\beta_{H}\left(\bar{\pi}_{W}-R^{H}-c_{W}\right)-c_{W} /\left(\theta_{S}-\theta_{W}\right)
\end{aligned}
$$

Proof. See Appendix 3.

Inequality (14) shows that the entrepreneur exerts high effort in the second period if and only if the marginal cost of effort exerted to increase the probability of

\footnotetext{
${ }^{25}$ The entrepreneur may have an incentive to report a high profit in a low-profit outcome in order to increase the residual payoff and the probability of continued financial support in the second period. However, the required transfer to the investor, which is contingent on the (untruthfully reported) high profit, would exceed the low profit the firm actually generates, resulting in liquidation according to the limited liability condition (see the optimal contract (FC3) in Appendix 4). Hence, the IC constraint that ensures the entrepreneur does not report high profits in a low-profit outcome is trivially satisfied and, therefore, omitted from the maximisation programme.

${ }^{26}$ It is assumed that the entrepreneur does not consume until the contract terminates.
} 
high profits, $c_{W} /\left(\theta_{S}-\theta_{W}\right)$, is more than offset by the profit differential, $\left(\pi_{H}-\pi_{L}\right)$. Intuitively, switching between effort choices must not be too costly; otherwise, it would be impossible to induce the entrepreneur to choose the high effort level. Notice that in the effort-elicitation model in Section 2, incentive mechanisms based on profitcontingent payments can be designed to induce the high effort level in both periods (see Contracts (FC1) and (FC2)). In the present hybrid setting, however, potential concealment of second-period profits makes the payoff of the entrepreneur irrelevant. As a result, the investor cannot design a credible incentive scheme to induce the entrepreneur to "work" in the second period, unless the parameters of the model automatically satisfy condition (14).

Condition (15) induces the entrepreneur to exert high effort in the first period by ensuring that the entrepreneur is better compensated in a high-profit outcome than in a low-profit one. Since effort and profits are related in the sense of the MLRP, the high effort level exerted leads to a higher probability of realising high profits, and consequently a higher entrepreneurial payoff. Similar to condition (7), the IC constraint (15) shows that the investor induces the entrepreneur to "work" by appropriately combining the two incentivising tools including profit-contingent payments and refinancing probabilities. Further examination of this condition in relation to the IC constraint (10) yields an interesting finding, as follows.

Lemma 3. Condition (15) should be satisfied automatically if and only if the IC constraint (10) and condition (14) both hold.

\section{Proof. See Appendix 3.}

Lemma 3 obtains an important finding that highlights the interaction of the two IC constraints of the model. Under condition (14), the financial contract that induces the entrepreneur to report first-period profits truthfully also elicits the high 
level of effort. In other words, in the presence of the truth-telling commitment, the effort-incentive constraint becomes redundant. This finding results from the relation of the two moral hazard problems considered in our model, i.e. hidden effort and unobservable (non-verifiable) profits. Exerting high effort ex ante increases the probability of realising a high profit (in the sense of the MLRP), which the entrepreneur can truthfully report to the investor and be rewarded with a higher payoff and greater probability of continued financial support. On the contrary, low effort exerted increases the likelihood of realising and reporting a low profit, thereby reducing the credibility of the truth-telling commitment. Regardless of the true state of nature, ex post, the entrepreneur who reports the low profit cannot credibly signal that he/she reports profits truthfully. Moreover, from the investor's perspective, using a standard revelation mechanism as in (10) that typically rewards the entrepreneur in a high-profit outcome can effectively incentivise the entrepreneur to produce and report the high profit ex post, thus also inducing the high effort level ex ante (following the MLRP). Hence, assuming condition (14), the IC constraint (10) provides incentives for the entrepreneur to report profits truthfully as well as to exert high effort. Technically, the results in Lemma 3 depend crucially on the assumption that better profit distributions are non-decreasing in effort choices in the sense of the MLRP (i.e. $\left.\theta_{S} \geq \theta_{W}\right)$

The novel finding in Lemma 3 has several important implications for financial contracting problems. First, it shows that under well-defined conditions, the optimal contract that solves a model with unobservable profits also elicits the high effort level. This suggests that results for an agency model with an ex post moral hazard problem due to unobservable cash flows can apply to a more general setting with an additional ex ante incentive problem due to hidden effort. Second, methodologically, this finding 
shows that in solving a model with two-dimensional incentive problems analogous to our model, one can abstract from effort issues and investigate a setting in which the only IC constraint is a standard revelation mechanism.

Lemma 3 allows us to consider programme (B) as a relaxed maximisation problem without (9). Further, by adopting the standard Kuhn-Tucker theorem, we are able to characterise the optimal financial contract as follows.

Proposition 2. The investor invests in the first period if and only if:

$\bar{\pi}_{W}-c_{W}-F \geq\left(F-\pi_{L}\right) /\left(1-\theta_{W}\right)$

The optimal financial contract specifies:

Contract (FC3): $\beta_{L}=0, \beta_{H}=1, R_{L}=\pi_{L}, R_{H} \leq \pi_{H}, R_{H}+R^{H}=\left(\bar{\pi}_{W}-c_{W}\right)+\pi_{L}$

Proof. See Appendix 4.

Corollary 1. Two special cases of the optimal contract (FC3) specify:

Contract (FC3a): $\beta_{L}=0, \beta_{H}=1, R_{L}=\pi_{L}, R_{H}=\bar{\pi}_{W}-c_{W}, R^{H}=\pi_{L}$

Contract (FC3b): $\beta_{L}=0, \beta_{H}=1, R_{L}=\pi_{L}, R_{H}=\bar{\pi}_{W}, R^{H}=\pi_{L}-c_{W}$

Proposition 2 and Corollary 1 reveal a number of interesting features of the optimal financial contract subject to both the truth-telling and effort-incentive constraints. Contract (FC3) as well as the two special cases (FC3a) and (FC3b) share some important characteristics with a simple debt contract. ${ }^{27}$ In particular, it specifies that on the announcement of the high profit, the entrepreneur makes a fixed transfer to the investor and receives second-round financing with certainty $\left(\beta_{H}=1\right)$; whereas on the announcement of the low profit, the entrepreneur has to transfer the entire profit to

\footnotetext{
${ }^{27}$ The debt optimality result also relies on the assumption that the entrepreneur is risk neutral. When the entrepreneur is risk averse, the debt contract is less appropriate because it must offer both effort inducement (truthful revelation) and insurance, which are potentially conflicting goals (Tirole, 2006). However, when efficient risk-sharing renegotiation is possible, the debt contract is again optimal (e.g. Hermalin and Katz, 1991; Dewatripont et al., 2003).
} 
the investor $\left(R_{L}=\pi_{L}\right)$ and faces liquidation $\left(\beta_{L}=0\right) .{ }^{28}$ From the investor's point of view, the termination threat is the main incentivising tool that elicits the high effort level and simultaneously induces truthful revelation of profits. This incentive scheme rewards the entrepreneur with refinancing in a high-profit outcome while withholds second period financial support in a low-profit outcome, where is a probability that the entrepreneur "shirks" and/or conceals the true profit. Hence, the termination threat provides incentives for the entrepreneur to report a high profit truthfully ex post, as well as to choose the high effort level ex ante. In short, the entrepreneur is incentivised to "work" and report the high profit level in order to avoid liquidation. Notice that at the end of the game, the termination threat is not available. In the absence of this incentivising tool, however, the unobservability and non-verification of profits may still induce the entrepreneur to "work" and capture the non-verifiable component of profits. ${ }^{29}$ Finally, as in Lemma 3, the results in proposition 1 are based on the MRLP, i.e., profit distributions are non-decreasing in the levels of effort. ${ }^{30}$

As analysed in Section 2, the termination threat in (FC3) gives rise to potential economic inefficiencies ex post because it would be suboptimal for both parties to terminate the contract when low profits are due to bad luck, but not due to low effort level exerted or untruthful reporting of profits. This finding illustrates an interesting contracting example in which some investment projects may go unfunded even

\footnotetext{
${ }^{28}$ In Appendix 4, we derive a feasible incentive scheme in which the investor always refinances the entrepreneur (see Contract (FC4)) but that contract is not optimal.

${ }^{29}$ Even in this case, the entrepreneur exerts high effort if and only if condition (14) is satisfied, i.e. switching effort must not be too costly, and the marginal cost of effort should be more than offset by the profit differential.

${ }^{30}$ The MRLP is a standard condition in effort-elicitation settings and one that is appropriate for different modelling of effort, including a discrete effort choice as in our paper or continuous effort choices as Innes (1990), Matthews (2001) and Dewatripont et al. (2003). In models with continuous effort, the entrepreneur still has an incentive to exert effort in order to produce high profits and avoid liquidation. Hence, the finding of our paper should be robust to this setting.
} 
though they have positive NPV. ${ }^{31}$ Notice further that the underinvestment incentive is more severe because condition (16), which ensures the investor's expected payoff to be non-negative, is even stricter than the assumption of non-negative NPV.

Contract (FC3) as the solution to the hybrid setting with hidden effort and unobservable (non-verifiable) profits is only partially consistent with the optimal contracts that solve the effort-elicitation model in Section 2. Specifically, the threat of liquidation that is an important characteristic of the debt-like optimal contract (FC3) is not always included in the effort-incentive scheme. Our results show that, in models with hidden effort, the liquidation threat is only used when effort is relatively costly (e.g. Contract ((FC2)) but in many situations (i.e. with lower costs of effort), the optimal contract ensures second-round financing with certainty and does not create underinvestment incentives (e.g. Contract FC1).

In terms of the transfers, the expected payoff of the investor in Contract (FC3) is smaller than that in the first-best outcomes derived in Section $2 .{ }^{32}$ If follows that the expected payoff of the entrepreneur is larger in (FC3) than in (FC1) and (FC2). This interesting finding demonstrates that in the presence of an additional moral hazard problem due to unobservable and non-verifiable profits, the investor must increase the payment to the entrepreneur in order to provide greater incentives for the latter party to report profits truthfully. In sum, while (FC3) is the optimal incentive scheme that can elicit high effort and induce truthful revelation of profits simultaneously, it does not reach the 'first-best' equilibrium as the optimal contracts (FC1) and (FC2) do in Section 2 .

\footnotetext{
${ }^{31}$ See Myers (1977) for alternative agency arguments that predict underinvestment.

${ }^{32}$ This can be verified easily by comparing the investor's objective function in (FC1), (FC2) and (FC3), respectively, while taking into consideration condition (14).
} 
Compared to existing two-period models in the literature, Contract (FC3) is generally consistent with the simple debt contract derived in Bolton and Scharfstein (1990). ${ }^{33}$ As a benchmark, the optimal contract in the base Bolton and Scharfstein model would specify $\left\{\beta_{L}=0, \beta_{H}=1, R_{L}=\pi_{L}, R_{H}=\bar{\pi}, R^{H}=\pi_{L}\right\}$ where $\bar{\pi}$ is the expected profits. Clearly, the two special cases (FC3a) and (FC3b) are broadly similar to the above benchmark contract. The general class of contracts specified in (FC3) only differs from the benchmark contract in one aspect, in that the sizes of transfers to the investor are relatively lower in a high-profit outcome. This result is appropriate because in effort-elicitation models, the entrepreneur requires a higher payoff in order to offset the cost of effort.

Finally, our finding is generally consistent with "staged capital arrangements", a financing technique widely used in venture capital in which the venture capitalist rarely invests the entire amount at once, but will provide the entrepreneur with funding in discrete stages over time (Sahlman, 1990; Megginson, 2006; Gompers, 2007). Initially, the venture capitalist provides funding to finance the firm's start-up needs such as R\&D implementation, completion of design, pilot production, etc. Conditional on the firm achieving the intended outcome, the venture capitalist will provide further funding for the next development stage such as test-marketing and full-scale production. Our contracting framework suggests that "staged capital infusion" helps mitigate moral hazard and creates incentives for the entrepreneur to maximise the firm value. The mechanism that requires the entrepreneur to return to

\footnotetext{
${ }^{33}$ This is, however, inconsistent with Povel and Raith (2004), who consider an analogous financing model with unobservable profits and hidden effort but find the optimal contract to be a non-simple debt contract. Notice that their model assumes that exerting low effort is first-best.
} 
the venture capitalist for further funding is shown to deter both "shirking" and concealment of true profits. $^{34}$

\section{Extensions with Endogenous Costs of Effort}

Thus far, we model the entrepreneur's payoff as retained earnings (profits after transfers) less the cost of effort, which is a (linear) function and independent of transfers to the investor. In this section, we examine a more realistic setting in which the entrepreneur's payoff function becomes non-linear, as the cost of effort is endogenous and partly affected by the size of transfers.

We consider a principal-agent framework in which the agent's productivity and utility are affected by not only extrinsic work motivation factors (e.g. pecuniary pay and rewards), but also by intrinsic work motivation factors, such as the agent's interest in the project, the nature of the agent's personal relationship with the principal, the agent's level of participation in decision-making process, the level of being supervised, controlled and manipulated, etc (see Frey, 1997; Murdock, 2002; Benabou and Tirole, 2003). In our contracting framework, we assume that the degree of control imposed by the investor over the entrepreneur, in the form of end-of-period transfers, has a negative impact on the way in which the entrepreneur evaluates (dis)utility. All else being equal, the higher the size of transfers, the higher the entrepreneur's cost of effort. The intuition behind this assumption is that the entrepreneur who makes high transfers to the investor perceives being controlled and underpaid, and thus has a tendency to reduce this inequality by lowering his/her intrinsic work motivation and performance, which in turn raises the cost of effort. In

\footnotetext{
${ }^{34}$ Notice, however, that stage financing might induce the entrepreneur to engage in "window dressing" and manipulating short-term performance to avoid liquidation (e.g. Cornelli and Yosha, 2003). Convertible securities can be designed to prevent such behaviour and recent empirical research shows that convertible securities (especially convertible stock) are in fact the most popular form of venture capital contracts (Kaplan and Strömberg, 2003).
} 
sum, the entrepreneur's cost of effort is positively affected by the size of transfers and is endogenous to this feature of the contract, thus potentially complicating the financial contracting problem. For example, while a higher transfer implies a higher likelihood that the investor provides second-round financing, it also leads to higher entrepreneurial effort costs and, as a result, creates more incentive for the entrepreneur to "shirk". We next turn to examine whether a simple debt contract similar to (FC3) is robust to this setting.

To address the endogeneity problem, we formulate the cost of effort function as an implicit function in the size of transfers:

$c_{i k}=c_{k}^{0}+g_{i}$ and $c^{i k}=c_{k}^{0}+g^{i}$

where $c_{i k}$ and $c^{i k}$ denote the entrepreneur's cost of effort in the first and second periods, respectively, with $i=L, H$, and $k=W, S . g(\cdot)$ is an implicit function of the transfers to the investor and is twice continuously differentiable: $g_{i}$ and $g^{i}$ are contingent on the first- and second-period transfers $R_{i}$ and $R^{i}$, respectively. Further assume the first-order derivative of $g(\cdot)$ is non-negative (i.e. $\partial g / \partial R_{i} \geq 0$ and $\left.\partial g / \partial R^{i} \geq 0\right)$, implying the cost of effort is non-decreasing in the size of transfers. The term $c_{k}^{0}$, with $k=W, S$, can be interpreted as the fixed cost of effort when the investor's control has no effects on the entrepreneur's cost of effort. Note that $c_{W}^{0}>c_{S}^{0} \geq 0$, i.e. the higher effort, the higher disutility. We also assume that $c_{S}^{0}=0$ and replace $\left(c_{W}^{0}-c_{S}^{0}\right)$ with $c_{W}^{0}$.

The maximisation programme (C) is analogous to $(\mathrm{B})$ with respect to the objective function and the IC, LL and IR constraints, except that effort costs are in a general functional form given by (17). The IC constraint that deters the entrepreneur from "shirking" in both periods becomes: 
$\theta_{W}\left[\pi_{L}-R_{L}-c_{L W}+\beta_{L}\left(\bar{\pi}_{W}-R^{L}-c^{L W}\right)\right]+\left(1-\theta_{W}\right)\left[\pi_{H}-R_{H}-c_{H W}+\beta_{H}\left(\bar{\pi}_{W}-R^{H}-c^{H W}\right)\right]$

$\geq \theta_{j}\left[\pi_{L}-R_{L}-c_{L j}+\beta_{L}\left(\bar{\pi}_{k}-R^{L}-c^{L k}\right)\right]+\left(1-\theta_{j}\right)\left[\pi_{H}-R_{H}-c_{H j}+\beta_{H}\left(\bar{\pi}_{k}-R^{H}-c^{H k}\right)\right]$

where $k=S$ if $j=W, k=W, S$ if $j=S$.

The IC constraint that induces truthful revelation of first-period profits is:

$\pi_{H}-R_{H}-c_{H W}+\beta_{H}\left(\bar{\pi}_{W}-R^{H}-c^{H W}\right) \geq \pi_{H}-R_{L}-c_{L W}+\beta_{L}\left(\bar{\pi}_{W}-R^{L}-c^{L W}\right)$

Finally, the usual IR constraint requires:

$\theta_{S}\left[\pi_{L}-R_{L}-c_{L S}+\beta_{L}\left(\bar{\pi}_{S}-R^{L}-c^{L S}\right)\right]+\left(1-\theta_{S}\right)\left[\pi_{H}-R_{H}-c_{H S}+\beta_{H}\left(\bar{\pi}_{S}-R^{H}-c^{H S}\right)\right] \geq 0$

where $k=S$ if $j=W, k=W, S$ if $j=S$.

In order to characterise the optimal contract, we follow the strategy adopted in the previous sections and first analyse the IC constraint (18).

Lemma 4. The IC constraint (18) that requires the entrepreneur to exert high effort in the first period is satisfied automatically if and only if the IC constraint (19) and condition (21) both hold.

$\pi_{L} \leq \pi_{H}-c_{W}^{0} /\left(\theta_{S}-\theta_{W}\right)$

\section{Proof. See Appendix 5.}

Lemma 4 reveals two important results about the relationship between the truth-telling and effort-incentive constraints of the model. First, similar to (14), condition (21) shows that the optimal contract elicits high effort in the second period only when the marginal cost of effort is more than offset by the profit differential. Second, under condition (21), the IC constraint (18) that induces high effort in the first period is automatically satisfied if the truth-telling constraint (19) holds. As Lemma 3 shows, this interesting finding obtains because effort affects the probabilities of high versus low profits in a manner consistent with the MLRP. 
Intuitively, the entrepreneur can only credibly convince the investor that he/she exerts high effort and reports profits truthfully by reporting a high profit level.

Lemma 4 extends Lemma 3 in that it shows the results regarding the relationship between the two IC constraints of the model hold true in a richer setting when entrepreneurial cost of effort is endogenous and partly affected by the size of transfers. Generalisation of the functional form of the entrepreneur's payoff does not alter the results of the model: the optimal contract that solves a model with unobservable profits also elicits the high effort level. As in programme (B), this finding allows us to treat the present contracting problem as a relaxed maximisation programme without the IC constraint (18). The results are presented in Lemma 5 and Proposition 3 as follows.

Lemma 5. At optimums, the entrepreneur is financed with certainty if a high profit is reported in the first period $\left(\beta_{H}=1\right)$. The maximisation program becomes:

$f=-F+\theta_{W} \pi_{L}+\left(1-\theta_{W}\right)\left(R_{H}+R^{H}-F\right)$

where $R_{H}+R^{H}=\left(\bar{\pi}_{W}-c_{W}^{0}\right)+\left(\pi_{L}+g\left(\pi_{L}\right)\right)-\left(g_{H}+g^{H}\right)$

Proof: See Appendix 6.

Proposition 3. The features of the optimal contract depend on the curvature of the cost function, $g(\cdot)$. If it is a convex function, the contract specifies:

Contract (FC5): $\beta_{L}=0, \beta_{H}=1, R_{L}=\pi_{L}, R_{H}=R^{H}=R^{*}$ where $R^{*}+g\left(R^{*}\right)=0.5\left[\left(\bar{\pi}_{W}-c_{W}^{0}\right)+\pi_{L}+g\left(\pi_{L}\right)\right]$.

If $g$ is a concave function, the optimal contract specifies:

Contract (FC6): $\beta_{L}=0, \beta_{H}=1, R_{L}=\pi_{L}, R_{H}=\pi_{H}, R^{H}=R^{* *}$ where $R^{* *}+g\left(R^{* *}\right)=\left(\bar{\pi}_{W}-c_{W}^{0}\right)-\left(\pi_{H}-\pi_{L}\right)-\left(g\left(\pi_{H}\right)-g\left(\pi_{L}\right)\right)$

Proof: See Appendix 6. 
Lemma 5 and Proposition 3 contain several important results. First, both optimal contracts derived in Proposition 3 are broadly consistent with Contract (FC3) and bear resemblance to the debt-like contract derived in prior models with unobservable profits (e.g. Bolton and Scharfstein, 1990). Importantly, both profitcontingent payments and the liquidation threat are used in these incentive schemes. However, the concavity of the entrepreneur's cost of effort function determines the size of transfers in a high-profit outcome. We consider two cases. If the effort cost function is convex, the marginal cost of effort is increasing in the size of transfers, i.e. the entrepreneur is strongly averse to external control, then the first and second-period transfers in a high-profit outcome are set equal, $R_{H}=R^{H}=R^{*}$ (where $R^{*}$ is given by (23)), and Contract (FC5) is optimal and fairly similar to (FC3). ${ }^{35}$ If the cost of effort is a concave function, i.e. the marginal cost of effort is decreasing in the size of transfers, then the optimal incentive scheme is Contract (FC6) with $R_{H}=\pi_{H}$, and $R^{H}=R^{* *}$ (where $R^{* *}$ is given by (25)). Unlike Contracts (FC3) or (FC5), however, Contract (FC6) requires that the first-period transfer in a high-profit outcome is equal to the entire profit. This specification leaves the entrepreneur with a zero payoff in the first period; even though the entrepreneur's expected payoff over the two periods is non-negative. Intuitively, in the concave case, the investor can extract more profit from the entrepreneur, who has a relatively lower degree of aversion to the external control. This makes Contract (FC6) depart slightly from a simple debt contract in which the repayment to the investor in a high profit state should be no greater than the face value of the debt. The finding suggests that non-linearity via endogenous costs of effort in the presence of concavity can render the optimal debt-like contract nonsimple.

\footnotetext{
${ }^{35}$ Further, the specific functional form of the cost function determines the size of these transfers.
} 


\section{Conclusions}

In this paper, we study financial contracting under a two-period financing framework and make two contributions to the literature. First, we have investigated a hybrid model with double moral hazard due to hidden entrepreneurial effort and nonverifiable profits. The incentive scheme that solves the model, therefore, must induce the entrepreneur to exert the first-best effort and report end-of-period profits truthfully. Second, we have adopted recent approaches in the industrial-organisation literature to financial contracting and considered a more realistic setting in which the entrepreneur's cost of effort is endogenously determined by the investor's degree of control in the form of transfers. We have explicitly allowed for this endogeneity problem by modelling the entrepreneur's cost of effort as a general function in transfers.

The paper has obtained several interesting results. We have shown that under well-defined conditions the optimal contract that induces truthful reporting of profits also elicits effort. This finding has important implications because it suggests results for models with non-verifiable cash flows can apply appropriately to models with an additional incentive problem caused by hidden effort. It also provides a novel methodological approach for future research whereby one may solve a model with double moral hazard by abstracting from ex ante effort issues and focusing on a simplified setting with ex post unobservable profits.

Importantly, with a few exceptions, all the optimal contracts derived in the paper bear significant resemblance to a debt contract. Specifically, these contracts force termination in a low-profit outcome and promise refinancing and continuation of operation in a high-profit outcome. Such optimal contract is incentive compatible in hybrid models with both unobservable (non-verifiable) profits and hidden effort 
because the termination threat credibly disciplines the entrepreneur who "shirks" and/or conceals true profits.

Our analysis has also shown that the structure of the optimal contract is robust in the general case where the entrepreneur's payoff function is endogenous and nonlinear in transfers. In this setting, however, the transfers to the investor in a high-profit outcome are determined by the specific functional form of the effort cost function. In the concave utility case, for example, the endogeneity and non-linearity problem may render the optimal debt-like contract non-simple.

Overall, the results have demonstrated the usefulness of a debt-like contract as an optimal incentive scheme in settings with double moral hazard and potential endogenous effort costs. This finding helps explain why debt financing is generally the most popular source of external finance in the real world (Tirole, 2006; Hillier et al., 2008), where there exists asymmetric information, moral hazard and non-linearity. 


\section{References}

Allen, F., Winton, A., 1995. Corporate Financial Structure, Incentives and Optimal Contracting, in Jarrow, R., Maksimovic, V., Ziemba, W. (Eds), Handbooks of Finance, North-Holland, Amsterdam, 693-719.

Benabou, R., Tirole, J., 2003. Intrinsic and Extrinsic Motivation. Review of Economic Studies 70, 489-520.

de Bettignies, J-E., 2008. Financing the Entrepreneurial Venture. Management Science 54, 151-166.

Bolton, P., Scharfstein, D., 1990. A Theory of Predation-based on Agency Problems in Financial Contracting. American Economic Review 80, 93-106.

Biais, B., Maiotti, T., Plantin G., Rochet, J.C., 2004. Dynamic Security Design and Pricing. Working Paper, Toulouse University.

Cornelli, F., Yosha, O., 2003. Stage Financing and the Role of Convertible Securities. Review of Economic Studies 70, 1-32.

DeMarzo, P.M., Fishman, M.J., 2007a. Agency and Optimal Investment Dynamics. Review of Financial Studies 20, 151-188.

DeMarzo, P.M., Fishman, M.J., 2007b. Optimal Long-Term Financial Contracting. Review of Financial Studies 20, 2079-2128.

DeMarzo, P.M., Sannikov, Y., 2006. Optimal Security Design and Dynamic Capital Structure in a Continuous-Time Agency Model. Journal of Finance 61, 26812724.

Dewatripont, M., Legros, P., Matthews, S., 2003. Moral Hazard and Capital Structure Dynamics. Journal of the European Economic Association 1, 890-930.

Dionne, G., Viala, P., 1994. Moral Hazard, Renegotiation and Debt. Economic Letters 46, 113-119. 
Dybvig, P., Wang, Y., 2002. Debt and Equity. Working Paper, Washington University at St. Louis and Boston University.

Faure-Grimaud, A., 2000. Product Market Competition and Optimal Debt Contracts: The Limited Liability Effect Revisited. European Economic Review 44, 1823-1840.

Faure-Grimaud, A., Mariotti, 1999. Optimal Debt Contracts and the SingleCrossing Condition. Economics Letters 65, 85-99.

Fluck, S. 1998. Optimal Financial Contracting: Debt versus Outside Equity. Review of Financial Studies 11, 383-418.

Frey, B.S., 1997. On the Relationship between Intrinsic and Extrinsic Work Motivation. International Journal of Industrial Organisation 15, 427-439.

Fudenberg, D., Tirole, J., 1990. Moral Hazard and Renegotiation in Agency Contracts. Econometrica 58, 1279-1320.

Gale, D., Hellwig, M., 1985. Incentive-Compatible Debt Contracts: The OnePeriod Problem. Review of Economic Studies 52, 647-663.

Gompers, P., 2007. Venture Capital, in Eckbo (ed) Handbook of Corporate Finance Vol. 1, Oxford: North Holland.

Grossman, S., Hart, O., 1983. An Analysis of the Principal-Agent Problem. Econometrica, 51, pp. 7-45.

Hart, O., 1995. Firms, Contracts, and Financial Structure, Oxford: Oxford University Press.

Hart, O., 2001. Financial Contracting, Journal of Economic Literature 39, 1079-1100.

Hart, O., Moore, J., 1989. Default and Renegotiation: A Dynamic Model of Debt. Working Paper, Harvard Business School. 
Hart, O., Moore, J., 1994. A Theory of Debt Based on the Inalienability of Human Capital. Quarterly Journal of Economics 109, 841-879.

Hart, O., Moore, J., 1998. Default and Renegotiation: A Dynamic Model of Debt. Quarterly Journal of Economics 113, 1-41.

Hermalin, B., Katz, M., 1991. Moral Hazard and Verifiability: The Effects of Renegotiation in Agency. Econometrica 59, 1735-1753.

Hillier, D., Grinblatt, M., Titman, S, 2008. Financial Markets and Corporate Strategy. European Edition. London: McGraw-Hill Education.

Holmstrom, B. 1979. Moral Hazard and Observability. Bell Journal of Finance 10, pp. 74-91.

Innes, R.D., 1990. Limited Liability and Incentive Contracting with Ex-ante Action Choices. Journal of Economic Theory 52, 45-67.

Jensen, M., Meckling, W., 1976. Theory of the Firm: Managerial Behavior, Agency Costs and Ownership Structure. Journal of Financial Economics 3, 305-360. Kaplan, S.N., Strömberg, P., 2003. Financial Contracting Theory Meets the Real World: An Empirical Analysis of Venture Capital Contracts. Review of Economic Studies 70, 281-316.

Laffont, J.J., Tirole, J., 1986. Using Cost Observation to Regulate Firms. Journal of Political Economy 94, 614-641.

Lawarree, J.P., Audenrode, M.A.V., 1996. Optimal Contract, Imperfect Output Observation, and Limited Liability. Journal of Economic Theory 71, 514-531. Matthews, S. A., 2001. Renegotiating Moral Hazard Contracts under Limited Liability and Monotonicity. Journal of Economic Theory 97, 1-29.

Mirrless, J.A., 1979. The Theory of Moral Hazard and Unobservable Behaviour: Part 1. Review of Economic Studies 66, 3-21. 
Megginson, W.L., 2004. Toward a Global Model of Venture Capital. Journal of Applied Corporate Finance 16, 89-107.

Murdock, K., 2002. Intrinsic Motivation and Optimal Incentive Contracts. Rand Journal of Economics 33, 650-671.

Myers, S.C., 1977. Determinants of Corporate Borrowing. Journal of Financial Economics 5, 145-175.

Myers, S.C., 2000. Outside Equity. Journal of Finance 55, 1005-1037.

Sahlman, W.A. 1990. The Structure and Governance of Venture Capital Organisations. Journal of Financial Economics 27, 473-521.

Sannikov, Y., 2006. A Continuous-Time Version of the Principal-Agent Problem. Working paper, University of California at Berkeley.

Sappington, D., 1983. Limited Liability Contracts between Principal and Agent. Journal of Economic Theory 29, 1-21.

Snyder, C.M., 1996. Negotiation and Renegotiation of Optimal Financial Contracts under the Threat of Predation. Journal of Industrial Economics 44, 352-343.

Rogerson, W.P., 1985. The First-Order Approach to Principal-Agent Problems. Econometrica 53, 1357-1368.

Ross, S., 1973. The Economics Theory of Agency: The Principal's Problem. American Economic Review 63, 134-139.

Povel, P., Raith, M., 2004. Optimal Debt with Unobservable Investment. Rand Journal of Economics 35, 599-616.

Tirole, J. 2006. The Theory of Corporate Finance. Oxford: Princeton University Press.

Townsend, R. 1979. Optimal Contracts and Competitive Markets with Costly State. Journal of Economic Theory 22, 265-293. 
Tchistyi, A., 2005. Security Design with Correlated Hidden Cash Flows: The Optimality of Performance Pricing. Working paper, Stanford University.

Williams, N., 2005. On Dynamic Principal-Agent Problems in Continuous Time. Working Paper, Princeton University.

Willner, J., 1999. Market Structure, Corporate Objectives and Cost Efficiency. in Cowling, K. (Ed), Industrial Policy in Europe: Theoretical Perspectives and Practical Proposals, London: Routledge.

Zou, L., 1995. Incentive Contracting with Hidden Choices of Effort and Risk. Economics Letters 47, 311-316. 


\section{Appendix 1. Proof of Lemma 1}

In order to prove Lemma 1, we examine four possible combinations of the entrepreneur's effort choices over the two periods including \{(working/working), (working/shirking), (shirking/working), (shirking/shirking)\}. The IC constraint (2) must induce the manager to exert high effort in both periods, and thus consists of three conditions, which we will now examine in turn.

The first condition is Utility(working/working) $\geq U t i l i t y$ (working/shirking):

$\theta_{W}\left[\left(\pi_{L}-R_{L}-c_{W}\right)+\beta_{L}\left(\bar{\pi}_{W}-\bar{R}_{W}-c_{W}\right)\right]+\left(1-\theta_{W}\right)\left[\left(\pi_{H}-R_{H}-c_{W}\right)+\beta_{H}\left(\bar{\pi}_{W}-\bar{R}_{W}-c_{W}\right)\right]$ $\geq \theta_{W}\left[\left(\pi_{L}-R_{L}-c_{W}\right)+\beta_{L}\left(\bar{\pi}_{S}-\bar{R}_{S}-c_{S}\right)\right]+\left(1-\theta_{W}\right)\left[\left(\pi_{H}-R_{H}-c_{W}\right)+\beta_{H}\left(\bar{\pi}_{S}-\bar{R}_{S}-c_{S}\right)\right]$ which, after some arrangements, is equivalent to :

$\pi_{L}-R^{L} \leq \pi_{H}-R^{H}-c_{W} /\left(\theta_{S}-\theta_{W}\right)$

where we use $\theta_{W} \beta_{L}+\left(1-\theta_{W}\right) \beta_{H}>0$ and assume, without loss of generalisation, that $c_{S}=0$, thereby replacing $\left(c_{W}-c_{S}\right)$ everywhere by $c_{W}$ (where $\left.c_{W} \geq 0\right)$.

The next condition is Utility(working/working) $\geq U$ tility(shirking/working):

$\theta_{W}\left[\left(\pi_{L}-R_{L}-c_{W}\right)+\beta_{L}\left(\bar{\pi}_{W}-\bar{R}_{W}-c_{W}\right)\right]+\left(1-\theta_{W}\right)\left[\left(\pi_{H}-R_{H}-c_{W}\right)+\beta_{H}\left(\bar{\pi}_{W}-\bar{R}_{W}-c_{W}\right)\right]$ $\geq \theta_{S}\left[\left(\pi_{L}-R_{L}-c_{S}\right)+\beta_{L}\left(\bar{\pi}_{W}-\bar{R}_{W}-c_{W}\right)\right]+\left(1-\theta_{S}\right)\left[\left(\pi_{H}-R_{H}-c_{S}\right)+\beta_{H}\left(\bar{\pi}_{W}-\bar{R}_{W}-c_{W}\right)\right]$ which can be arranged to yield:

$\pi_{L}-R_{L} \leq \pi_{H}-R_{H}-c_{W} /\left(\theta_{S}-\theta_{W}\right)+\left(\beta_{H}-\beta_{L}\right)\left(\bar{\pi}_{W}-\bar{R}_{W}-c_{W}\right)$

The last condition is Utility(working/working) $\geq U t i l i t y$ (shirking/shirking):

$\theta_{W}\left[\left(\pi_{L}-R_{L}-c_{W}\right)+\beta_{L}\left(\bar{\pi}_{W}-\bar{R}_{W}-c_{W}\right)\right]+\left(1-\theta_{W}\right)\left[\left(\pi_{H}-R_{H}-c_{W}\right)+\beta_{H}\left(\bar{\pi}_{W}-\bar{R}_{W}-c_{W}\right)\right]$ $\geq \theta_{S}\left[\left(\pi_{L}-R_{L}-c_{S}\right)+\beta_{L}\left(\bar{\pi}_{S}-\bar{R}_{S}-c_{S}\right)\right]+\left(1-\theta_{S}\right)\left[\left(\pi_{H}-R_{H}-c_{S}\right)+\beta_{H}\left(\bar{\pi}_{S}-\bar{R}_{S}-c_{S}\right)\right]$

and we will now show that this condition is automatically satisfied given the first two conditions. Prove that Utility(working/working) $\geq U$ Utility(shirking/working) $\geq$ 
Utility(shirking/shirking). Note that the former inequality is assumed to hold true by (26), so it remains to prove that the latter inequality is satisfied, that is,

$\theta_{S}\left[\left(\pi_{L}-R_{L}-c_{S}\right)+\beta_{L}\left(\bar{\pi}_{W}-\bar{R}_{W}-c_{W}\right)\right]+\left(1-\theta_{S}\right)\left[\left(\pi_{H}-R_{H}-c_{S}\right)+\beta_{H}\left(\bar{\pi}_{W}-\bar{R}_{W}-c_{W}\right)\right]$

$\geq \theta_{S}\left[\left(\pi_{L}-R_{L}-c_{S}\right)+\beta_{L}\left(\bar{\pi}_{S}-\bar{R}_{S}-c_{S}\right)\right]+\left(1-\theta_{S}\right)\left[\left(\pi_{H}-R_{H}-c_{S}\right)+\beta_{H}\left(\bar{\pi}_{S}-\bar{R}_{S}-c_{S}\right)\right]$

which, after some arrangements, can be shown to be equivalent to:

$\left[\left(\pi_{H}-\pi_{L}\right)\left(\theta_{S}-\theta_{W}\right)-\left(R^{H}-R^{L}\right)\left(\theta_{S}-\theta_{W}\right)-\left(c_{W}-c_{S}\right)\right]\left[\theta_{S} \beta_{L}+\left(1-\theta_{S}\right) \beta_{H}\right] \geq 0$, which

is obvious because the first expression is non-negative by (26), and the second

expression is positive by assumption.

\section{Appendix 2. Proof of Proposition 1}

The proof of Proposition 1 proceeds in three steps. First, we formulate the KuhnTucker Lagrangian function and derive the first-order conditions. Second, we solve for the Lagrangian parameters by analysing the first-order conditions and the complementary slackness conditions. Third, we consider four cases where the two IC constraints are either binding or binding.

First, problem (A) can be rewritten under the Kuhn-Tucker framework:

$\operatorname{Max} f\left(\beta_{i}, R_{i}, R^{i}\right)=-F+\theta_{W}\left(R_{L}+\beta_{L}\left(\bar{R}_{W}-F\right)\right)+\left(1-\theta_{W}\right)\left(R_{H}+\beta_{H}\left(\bar{R}_{W}-F\right)\right)$

Subject to

$$
\begin{aligned}
& \left(R^{H}-R^{L}\right) \leq\left(\pi_{H}-\pi_{L}\right)-c_{W} /\left(\theta_{S}-\theta_{W}\right) \\
& \left(R_{H}-R_{L}\right)-\left(\beta_{H}-\beta_{L}\right)\left[\left(\theta_{W} \pi_{L}+\left(1-\theta_{W}\right) \pi_{H}-c_{W}\right)-\theta_{W} R^{L}-\left(1-\theta_{W}\right) R^{H}\right] \\
& \leq\left(\pi_{H}-\pi_{L}\right)-c_{W} /\left(\theta_{S}-\theta_{W}\right) \\
& R_{L} \leq \pi_{L} \\
& R_{H} \leq \pi_{H}
\end{aligned}
$$


$R^{L} \leq \pi_{L}$

$R^{H} \leq \pi_{H}$

The Kuhn-Tucker Lagrangian function is:

$\left.\operatorname{Max} L=-F+\theta_{W} R_{L}+\left(1-\theta_{W}\right) R_{H}+\left(\theta_{W} \beta_{L}+\left(1-\theta_{W}\right) \beta_{H}\right)\left(\theta_{W} R^{L}+\left(1-\theta_{W}\right) R^{H}-F\right)\right)$

$-\lambda_{1}\left[\left(R^{H}-R^{L}\right)-\left(\pi_{H}-\pi_{L}-c_{W} /\left(\theta_{S}-\theta_{W}\right)\right)\right]$

$-\lambda_{2}\left[\left(R_{H}-R_{L}\right)-\left(\beta_{H}-\beta_{L}\right)\left[\left(\theta_{W} \pi_{L}+\left(1-\theta_{W}\right) \pi_{H}-c_{W}\right)-\theta_{W} R^{L}-\left(1-\theta_{W}\right) R^{H}\right]-\left[\left(\pi_{H}-\pi_{L}\right)-c_{W} /\left(\theta_{S}-\theta_{W}\right)\right]\right]$

$-\lambda_{3}\left[R_{L}-\pi_{L}\right]-\lambda_{4}\left[R_{H}-\pi_{H}\right]-\lambda_{5}\left[R^{L}-\pi_{L}\right]-\lambda_{6}\left[R^{H}-\pi_{H}\right]$

where $\lambda_{i}(i=1 . .6)$ are non-negative parameters.

Second, assume $\beta_{L}$ and $\beta_{H}$ are taken as given, the first-order conditions are:

$\partial L / \partial R_{L}=\theta_{W}+\lambda_{2}-\lambda_{3} \leq 0$

$\partial L / \partial R_{H}=\left(1-\theta_{W}\right)-\lambda_{2}-\lambda_{4} \leq 0$

$\partial L / \partial R^{L}=\left(\theta_{W} \beta_{L}+\left(1-\theta_{W}\right) \beta_{H}\right) \theta_{W}+\lambda_{1}-\lambda_{2}\left(\beta_{H}-\beta_{L}\right) \theta_{W}-\lambda_{5} \leq 0$

$\partial L / \partial R^{H}=\left(\theta_{W} \beta_{L}+\left(1-\theta_{W}\right) \beta_{H}\right)\left(1-\theta_{W}\right)-\lambda_{1}-\lambda_{2}\left(\beta_{H}-\beta_{L}\right)\left(1-\theta_{W}\right)-\lambda_{6} \leq 0$

$\partial L / \partial \lambda_{i} \geq 0$ where $i=1 . .6$

In addition, there are also complementary slackness conditions, which are not presented to save space. First, observe that transfers to the investor are positive, so conditions (34), (35), (36) and (37) should all bind, hence the following equations:

$\theta_{W}+\lambda_{2}-\lambda_{3}=0$

$\left(1-\theta_{W}\right)-\lambda_{2}-\lambda_{4}=0$

$\left(\theta_{W} \beta_{L}+\left(1-\theta_{W}\right) \beta_{H}\right) \theta_{W}+\lambda_{1}-\lambda_{2}\left(\beta_{H}-\beta_{L}\right) \theta_{W}-\lambda_{5}=0$

$\left(\theta_{W} \beta_{L}+\left(1-\theta_{W}\right) \beta_{H}\right)\left(1-\theta_{W}\right)-\lambda_{1}-\lambda_{2}\left(\beta_{H}-\beta_{L}\right)\left(1-\theta_{W}\right)-\lambda_{6}=0$ 
Further, combining (28) and (32) yields $R^{H}<\pi_{H}$, which, due to complementary slackness, obtains $\lambda_{6}=0$. Finally from (39), note that $\lambda_{3}>0$ because $\theta_{W}>0$ and $\lambda_{2} \geq 0$. This implies $R_{L}=\pi_{L}$ due to complementary slackness.

We proceed by examining four cases where two IC constraints are either binding or not binding: (i) $\lambda_{1}=\lambda_{2}=0$; (ii) $\lambda_{1} \neq 0$ and $\lambda_{2}=0$; (iii) $\lambda_{1} \neq 0$ and $\lambda_{2} \neq 0$; (iv) $\lambda_{1}=0$ and $\lambda_{2} \neq 0$.

Case 1: $\lambda_{1}=\lambda_{2}=0$ (both constraints are not binding). Since $\lambda_{6}=0$ and $\beta_{H}$ and $\beta_{L}$ cannot be both equal to 0 simultaneously, (42) is not satisfied. Hence, at least one IC constraint must bind.

Case 2: $\lambda_{1} \neq 0$ and $\lambda_{2}=0$ (at least the first IC constraint binds). From (40), $\lambda_{4}=1-\theta_{W}>0$. According the complementary slackness condition, $R_{H}=\pi_{H}$. Since $\lambda_{2}=0$ and $\lambda_{6}=0$, from (41) and (42), we easily derive $\lambda_{5}=\left(\theta_{W} \beta_{L}+\left(1-\theta_{W}\right) \beta_{H}\right)$, which is positive and implies $R^{L}=\pi_{L}$. The potential optimal contract is $\left\{R_{L}=\pi_{L}\right.$, $\left.R_{H}=\pi_{H}, R^{L}=\pi_{L}, R^{H}=\pi_{H}-c_{W} /\left(\theta_{S}-\theta_{W}\right)\right\}$. However, this contract does not satisfy the second IC constraint (29).

Case 3: $\lambda_{1} \neq 0$ and $\lambda_{2} \neq 0$ (both IC constraints bind). In this subsection, we will show that $R^{L}=\pi_{L}$ and based on this we will derive the optimal contract. Then we will find $\beta_{H}$ and $\beta_{L}$. First, suppose $R^{L}<\pi_{L}$, it follows $\lambda_{5}=0$. Since $\lambda_{6}=0$, from (41) and (42), $\lambda_{1}=0$ and $\lambda_{2}=0$, hence a contradiction. Thus, $R^{L}=\pi_{L}$. Given both IC constraints are binding, we can derive the optimal contract.

Contract (FC1): $R_{L}=\pi_{L}, R_{H}=\pi_{H}-c_{W} /\left(\theta_{S}-\theta_{W}\right)+\left(\beta_{H}-\beta_{L}\right)\left(1-\theta_{S}\right) c_{W} /\left(\theta_{S}-\theta_{W}\right)$, $R^{L}=\pi_{L}, R^{H}=\pi_{H}-c_{W} /\left(\theta_{S}-\theta_{W}\right)$ 
This contract satisfies the Kuhn-Tucker conditions and all the constraints of the model, including the IR constraint.

Next, derive $\beta_{H}$ and $\beta_{L}$ by substituting contract (FC1) into programme (A):

$f=-F+\theta_{W} R_{L}+\left(1-\theta_{W}\right) R_{H}+\left(\theta_{W} \beta_{L}+\left(1-\theta_{W}\right) \beta_{H}\right)\left(\theta_{W} R^{L}+\left(1-\theta_{W}\right) R^{H}-F\right)$

$=-F+\theta_{W} \pi_{L}+\left(1-\theta_{W}\right) \pi_{H}-\left(1-\theta_{S}\right) c_{W} /\left(\theta_{S}-\theta_{W}\right)+\beta_{H}\left(1-\theta_{W}\right)\left(\theta_{W} \pi_{L}+\left(1-\theta_{W}\right) \pi_{H}-F-c_{W}\right)$

$+\beta_{L}\left[\theta_{W}\left(\theta_{W} \pi_{L}+\left(1-\theta_{W}\right) \pi_{H}-F-c_{W}\right)-\left(1-\theta_{S}\right) c_{W} /\left(\theta_{S}-\theta_{W}\right)\right]$

Let $m=\bar{\pi}_{W}-F-c_{W}$ (and assume $\left.m \geq 0\right)$ and $n=\left(1-\theta_{S}\right) c_{W} /\left(\theta_{S}-\theta_{W}\right)$, the objective function becomes $f=m-n+\beta_{H}\left(1-\theta_{W}\right) m+\beta_{L}\left(\theta_{W} m-n\right)$. Since $m$ and $n$ are constant and $\left(1-\theta_{W}\right) m \geq 0$, maximising $f$ is equivalent to maximising $\beta_{H}$, hence $\beta_{H}=1$.

Finally, consider the sign of $\left(\theta_{W} m-n\right)$. If $\theta_{W} m-n \geq 0$ then $\beta_{L}=1$. Since $\theta_{W} m-n \geq 0, m \geq n$, the objective function is $m-n+\left(1-\theta_{W}\right) m+\left(\theta_{W} m-n\right) \geq 0$ and so the non-negativity condition is automatically satisfied. The optimal contract is (FC1) with $\beta_{L}=\beta_{H}=1$. If $\theta_{W} m-n<0$, then $\beta_{L}=0$. The objective function is nonnegative if and only if $m-n+\left(1-\theta_{W}\right) m \geq 0$, or equivalently, $\left(2-\theta_{W}\right) m \geq n$. In this case, the optimal contract is (FC1) with $\beta_{L}=0$ and $\beta_{H}=1$.

Case 4: $\lambda_{1}=0$ and $\lambda_{2} \neq 0$ (at least the second IC constraint binds). Proceed in three steps. First, we will derive the parameters of the Kuhn-Tucker Lagrangian function, and find $\beta_{H}$ and $\beta_{L}$. Second, we will derive the optimal contract. Finally, we will compare the optimal contract with the contract (FC1).

Given $\lambda_{1}=0, \lambda_{6}=0$, from (39), (40), (41) and (42), we are able to derive $\lambda_{2}=\left(\theta_{W} \beta_{L}+\left(1-\theta_{W}\right) \beta_{H}\right) /\left(\beta_{H}-\beta_{L}\right), \lambda_{3}=\beta_{H} /\left(\beta_{H}-\beta_{L}\right), \lambda_{4}=-\beta_{L} /\left(\beta_{H}-\beta_{L}\right)$, and 
$\lambda_{5}=0$. Further $\beta_{L}=0$ because $\lambda_{4} \geq 0$. Given $\beta_{L}=0$ and that the second IC constraint is binding, the original maximisation can be simplified to:

$f=-F+\theta_{W} \pi_{L}+\left(1-\theta_{W}\right) \pi_{H}+\beta_{H}\left(1-\theta_{W}\right)\left(\theta_{W} \pi_{L}+\left(1-\theta_{W}\right) \pi_{H}-F-c_{W}\right)-\left(1-\theta_{W}\right) c_{W} /\left(\theta_{S}-\theta_{W}\right)$ or $f=m-n+\beta_{H}\left(1-\theta_{W}\right) m$. Since $\left(1-\theta_{W}\right) m \geq 0$, the objective function $f$ is maximised when $\beta_{H}=1$. Further, the optimal contract must satisfy:

$$
\begin{aligned}
& R_{L}=\pi_{L} \\
& R^{L} \leq \pi_{L} \\
& \left(R^{H}-R^{L}\right) \leq\left(\pi_{H}-\pi_{L}\right)-c_{W} /\left(\theta_{S}-\theta_{W}\right) \\
& R_{H}-\left[\left(\theta_{W} \pi_{L}+\left(1-\theta_{W}\right) \pi_{H}-c_{W}\right)-\theta_{W} R^{L}-\left(1-\theta_{W}\right) R^{H}\right]=\pi_{H}-c_{W} /\left(\theta_{S}-\theta_{W}\right)
\end{aligned}
$$

The optimal contract specifies

Contract (FC2): $\beta_{L}=0, \beta_{H}=1, R_{L}=\pi_{L}$, $R_{H}=\pi_{H}+\left[(s-1)-[(s-1)-t] \theta_{W}-\theta_{S}\right] c_{W} /\left(\theta_{S}-\theta_{W}\right)$ $R^{L}=\pi_{L}-t c_{W} /\left(\theta_{S}-\theta_{W}\right) ; R^{H}=\pi_{H}-s c_{W} /\left(\theta_{S}-\theta_{W}\right)$, where $s$ and $t \in R^{+}$. For (28) and (31) to hold, it is required that $t \leq s-1,(s-1)-[(s-1)-t] \theta_{W}-\theta_{S} \leq 0$ and $t<1$. This class of contracts satisfies the Kuhn-Tucker theorem and all the constraints of the model including the IR constraint. Note that the objective function must satisfy $f=m-n+\beta_{H}\left(1-\theta_{W}\right) m \geq 0$, or $\left(2-\theta_{W}\right) m \geq n$.

Finally, compare the objective functions in (FC1) and (FC2). When $\theta_{W} m-n \geq 0$, the first contract is optimal since $m-n+\left(\theta_{W} m-n\right)+\left(1-\theta_{W}\right) m$ is larger than $m-n+\left(1-\theta_{W}\right) m$. When $\left(2-\theta_{W}\right) m \geq n>\theta_{W} m$, the two contracts (FC1) and (FC2) yield the same maximum value and the first contract is a special case of the second contract when $s=1$ and $t=0$. To summarise, the optimal contract takes the form of contract (FC1) when $\theta_{W} m-n \geq 0$, and (FC2) when $\left(2-\theta_{W}\right) m \geq n>\theta_{W} m$. 


\section{Appendix 3. Proof of Lemma 2 \& Lemma 3}

Proof of Lemma 2: As in Appendix 1, we examine four possible combinations of the entrepreneur's effort choices over the two periods including (working/working), (working/shirking), (shirking/working), (shirking/shirking)\}. The IC constraint (9) must induce the entrepreneur to exert the high effort level in both periods and consists of three conditions. The first condition is Utility(working/working) $\geq$ Utility (working/shirking), which can be simplified to:

$\pi_{L} \leq \pi_{H}-c_{W} /\left(\theta_{S}-\theta_{W}\right)$

where $\left(\theta_{W} \beta_{L}+\left(1-\theta_{W}\right) \beta_{H}>0\right)$ is used and $\left(c_{W}-c_{S}\right)$ is replaced with $c_{W}$. The next condition is Utility(working/working) $\geq U$ tility(shirking/working), which, after some arrangements, can be reduced to:

$\pi_{L}-R_{L}+\beta_{L}\left(\bar{\pi}_{W}-R^{L}-c_{W}\right) \leq \pi_{H}-R_{H}+\beta_{H}\left(\bar{\pi}_{W}-R^{H}-c_{W}\right)-c_{W} /\left(\theta_{S}-\theta_{W}\right)$

The third condition is Utility(working/working) $\geq$ Utility(shirking/shirking) and we will show that it is automatically satisfied given the first two conditions. Specifically, we will prove that Utility(working/working) $\geq U$ tility(shirking/working) $\geq$ Utility(shirking/shirking). The first inequality is true by (47), so we will prove the second inequality, $\left[\left(\pi_{H}-\pi_{L}\right)\left(\theta_{S}-\theta_{W}\right)-\left(c_{W}-c_{S}\right)\right]\left[\theta_{S} \beta_{L}+\left(1-\theta_{S}\right) \beta_{H}\right] \geq 0$, which is true because by (47) and $\theta_{S} \beta_{L}+\left(1-\theta_{S}\right) \beta_{H}>0$.To summarise, the IC constraint (9) implies conditions (47) and (48).

\section{QED}

Proof of Lemma 3: Condition (15) is a combination of condition (14) and the IC constraint (10). To prove that, one can arrange condition (15) to yield $\left(\pi_{H}-\pi_{L}\right)+\left[-R_{H}+R_{L}+\beta_{H}\left(\bar{\pi}_{W}-R^{H}-c_{W}\right)-\beta_{L}\left(\bar{\pi}_{W}-R^{L}-c_{W}\right)\right] \geq c_{W} /\left(\theta_{S}-\theta_{W}\right)$ 
Then, it is easy to show that this inequality is satisfied because the first term on the left hand side is greater than the expression $c_{W} /\left(\theta_{S}-\theta_{W}\right)$ by condition (14) and the second term is an arrangement of the IC constraint (10) and must be non-negative.

$Q E D$

\section{Appendix 4. Proof of Proposition 2}

The proof of Proposition 2 proceeds in three steps. First, we derive Kuhn-Tucker Lagrangian function for problem (B). Second, we find the first order derivatives and solve for the Lagrangian parameters. Third, we characterise the optimal contract by examining three cases when (i) $\beta_{L}=0$, (ii) $\beta_{L}=1$ and (iii) $0<\beta_{L}<1$.

First, rewrite problem (B) under the Kuhn-Tucker framework

$\operatorname{Max} f\left(\beta_{i}, R_{i}, R^{i}\right)=-F+\theta_{W}\left(R_{L}+\beta_{L}\left(R^{L}-F\right)\right)+\left(1-\theta_{W}\right)\left(R_{H}+\beta_{H}\left(R^{H}-F\right)\right)$

subject to

$$
\begin{aligned}
& R_{H}-R_{L}+\beta_{H} R^{H}-\beta_{L} R^{L} \leq\left(\beta_{H}-\beta_{L}\right)\left(\bar{\pi}_{W}-c_{W}\right) \\
& R_{L} \leq \pi_{L} \\
& R_{H} \leq \pi_{H} \\
& R_{L}+R^{L} \leq 2 \pi_{L} \\
& R_{H}+R^{H} \leq \pi_{H}+\pi_{L}
\end{aligned}
$$

under the condition $\pi_{H}-\pi_{L} \geq c_{W} /\left(\theta_{S}-\theta_{W}\right)$.

The Kuhn-Tucker Lagrangian function is

$\operatorname{Max} L=-F+\theta_{W} R_{L}+\theta_{W} \beta_{L}\left(R^{L}-F\right)+\left(1-\theta_{W}\right) R_{H}+\left(1-\theta_{W}\right) \beta_{H}\left(R^{H}-F\right)$

$-\lambda_{1}\left(R_{H}-R_{L}+\beta_{H} R^{H}-\beta_{L} R^{L}-\left(\beta_{H}-\beta_{L}\right)\left(\bar{\pi}_{W}-c_{W}\right)\right)$

$-\lambda_{2}\left(R_{L}-\pi_{L}\right)-\lambda_{3}\left(R_{H}-\pi_{H}\right)-\lambda_{4}\left(R_{L}+R^{L}-2 \pi_{L}\right)-\lambda_{5}\left(R_{H}+R^{H}-\pi_{H}-\pi_{L}\right)$

where $\lambda_{i}(i=1 . .5)$ are non-negative parameters. 
Second, following the strategy used to solve problem (A), we assume that $\beta_{L}$ and $\beta_{H}$ are taken as given. The first-order conditions are:

$\partial L / \partial R_{L}=\theta_{W}+\lambda_{1}-\lambda_{2}-\lambda_{4} \leq 0$

$\partial L / \partial R_{H}=\left(1-\theta_{W}\right)-\lambda_{1}-\lambda_{3}-\lambda_{5} \leq 0$

$\partial L / \partial R^{L}=\theta_{W} \beta_{L}+\lambda_{1} \beta_{L}-\lambda_{4} \leq 0$

$\partial L / \partial R^{H}=\left(1-\theta_{W}\right) \beta_{H}-\lambda_{1} \beta_{H}-\lambda_{5} \leq 0$

$\partial L / \partial \lambda_{i} \geq 0$ where $i=1 . .5$

There are also complementary slackness conditions, which are not presented to save space. Since transfers are not equal to zero, conditions (54), (55), (56) and (57) should all bind. We have a set of four simultaneous equations to solve for five parameters.

The solutions in terms of $\lambda_{1}$ (where $\lambda_{1} \in R^{+}$) are derived as follows:

$\lambda_{2}=\left(1-\beta_{L}\right)\left(\theta_{W}+\lambda_{1}\right)$

$\lambda_{3}=\left(1-\beta_{H}\right)\left(1-\theta_{W}-\lambda_{1}\right)$

$\lambda_{4}=\beta_{L}\left(\theta_{W}+\lambda_{1}\right)$

$\lambda_{5}=\beta_{H}\left(1-\theta_{W}-\lambda_{1}\right)$

Third, we will examine the following three cases: (i) $\beta_{L}=0$, and (ii) $\beta_{L}=1$ and (iii) $0<\beta_{L}<1$; and prove that the optimal contract only exists in the first case.

Case 1: $\beta_{L}=0$. It follows from (59) that $\lambda_{2}=\theta_{W}+\lambda_{1}>0$. Further due to complementary slackness $R_{L}=\pi_{L}$. The maximisation problem is:

$f=-F+\theta_{W} \pi_{L}+\left(1-\theta_{W}\right)\left(R_{H}+\beta_{H}\left(R^{H}-F\right)\right)$

and, thus, to maximise the objective function is to maximise the expression $\left(R_{H}+\beta_{H}\left(R^{H}-F\right)\right)$. Note that $R_{H}+\beta_{H}\left(R^{H}-F\right) \leq \beta_{H}\left(\bar{\pi}_{W}-c_{W}-F\right)+\pi_{L}$ by the IC 
constraint (49) and under the assumption $\bar{\pi}_{W}-c_{W}-F \geq 0$, the expression $\left(R_{H}+\beta_{H}\left(R^{H}-F\right)\right)$ is maximised when the IC constraint binds and $\beta_{H}=1$. Hence

\section{Contract (FC3):}

$\beta_{L}=0, \beta_{H}=1, R_{L}=\pi_{L}, R_{H} \leq \pi_{H}, R^{L} \leq \pi_{L}, R_{H}+R^{H}=\left(\bar{\pi}_{W}-c_{W}\right)+\pi_{L}$

This contract satisfies the Kuhn Tucker conditions and all constraints in the model including the IR constraint (though this IR constraint is not binding). Further, to ensure the investor's participation, the objective function must be non-negative:

$$
\begin{aligned}
& f=-F+\theta_{W} \pi_{L}+\left(1-\theta_{W}\right)\left(\bar{\pi}_{W}-c_{W}+\pi_{L}-F\right) \geq 0 \\
& \bar{\pi}_{W}-c_{W}-F \geq\left(F-\pi_{L}\right) /\left(1-\theta_{W}\right)
\end{aligned}
$$

Case 2: $\beta_{L}=1$. In this subsection, we characterise a feasible contract and then show that it is suboptimal as compared to Contract (FC3). First, since $\beta_{L}=1$, it follows from (61) that $\lambda_{4}=\theta_{W}+\lambda_{1}>0$. Due to complementary slackness $R_{L}+R^{L}=2 \pi_{L}$. The maximisation problem becomes:

$f=-F+\theta_{W}\left(2 \pi_{L}-F\right)+\left(1-\theta_{W}\right)\left(R_{H}+\beta_{H}\left(R^{H}-F\right)\right)$

Again, this is equivalent to maximising the expression $\left(R_{H}+\beta_{H}\left(R^{H}-F\right)\right)$.

Rearranging and subtracting $\beta_{H} F$ from both side of the IC constraint (49) yields $R_{H}+\beta_{H}\left(R^{H}-F\right) \leq \beta_{H}\left(\bar{\pi}_{W}-c_{W}-F\right)+2 \pi_{L}-\left(\bar{\pi}_{W}-c_{W}\right)$. As above, the expression $\left(R_{H}+\beta_{H}\left(R^{H}-F\right)\right)$ is maximised when the IC constraint binds and $\beta_{H}=1$. The feasible contract specifies

Contract (FC4): $\beta_{L}=1, \beta_{H}=1, R_{L} \leq \pi_{L}, R_{H} \leq \pi_{H}, R_{L}+R^{L}=2 \pi_{L}$, $R_{H}+R^{H}=2 \pi_{L}$ 
This contract satisfies the Kuhn Tucker conditions and all constraints of the model. The IR constraint is satisfied and not binding. An example of contract (FC4) is $\left\{\beta_{L}=1, \beta_{H}=1, R_{L}=\pi_{L}, R_{H}=\pi_{L}, R^{L}=\pi_{L}, R^{H}=\pi_{L}\right\}$.

Finally, we will show that contract (FC4) is suboptimal by comparing the objective function of this contract to that of contract (FC3). The objective function of contract (FC4) is

$$
f=-F+\theta_{W} \pi_{L}+\theta_{W}\left(\pi_{L}-F\right)+\left(1-\theta_{W}\right)\left(\pi_{L}+\pi_{L}-F\right)
$$

Comparing this to the objective function (64), first observe that $\theta_{W}\left(\pi_{L}-F\right)<0$ by assumption. Further, notice that $\pi_{L}+\pi_{L}-F \leq \bar{\pi}_{W}-c_{W}+\pi_{L}-F$ based on condition (47), $\pi_{H}-\pi_{L} \geq c_{W} /\left(\theta_{S}-\theta_{W}\right)$ and $\bar{\pi}_{W}-\pi_{L}=\left(1-\theta_{W}\right)\left(\pi_{H}-\pi_{L}\right)>\left(\theta_{S}-\theta_{W}\right)\left(\pi_{H}-\pi_{L}\right)$ $\geq c_{W}$. Since (66) is strictly less than (64), contract (FC4) is not an optimal contract.

Case 3: $0<\beta_{L}<1$. We will also show that in this case, the feasible contract is suboptimal, as compared to contract (FC3). First, it follows from (59) and (61) that $\lambda_{2} \neq 0$ and $\lambda_{4} \neq 0$. Further, due to complementary slackness, $R_{L}=\pi_{L}$ and $R_{L}+R^{L}=2 \pi_{L}$, that is, $R_{L}=R^{L}=\pi_{L}$. The maximisation problem becomes $f=-F+\theta_{W} \pi_{L}+\theta_{W} \beta_{L}\left(\pi_{L}-F\right)+\left(1-\theta_{W}\right)\left(R_{H}+\beta_{H}\left(R^{H}-F\right)\right)$

Without deriving the feasible contract, compare directly the two objective functions given by (64) and (67). First $\theta_{W} \beta_{L}\left(\pi_{L}-F\right)<0$, and from the IC constraint:

$$
\begin{aligned}
& R_{H}+\beta_{H} R^{H} \leq\left(\beta_{H}-\beta_{L}\right)\left(\bar{\pi}_{W}-c_{W}\right)+\pi_{L}+\beta_{L} \pi_{L}=\left[\beta_{H}\left(\bar{\pi}_{W}-c_{W}\right)+\pi_{L}\right]+\beta_{L}\left(\pi_{L}-\left(\bar{\pi}_{W}-c_{W}\right)\right) \\
& \left.<\beta_{H}\left(\bar{\pi}_{W}-c_{W}\right)+\pi_{L} \leq \bar{\pi}_{W}-c_{W}+\pi_{L} \text { as } \pi_{L}-\left(\bar{\pi}_{W}-c_{W}\right)<0 \text { (see above }\right) .
\end{aligned}
$$

Thus, (67) is strictly less than (64), and so any feasible contract that specifies $0<\beta_{L}<1$ is not a part of an optimal contract. 


\section{Appendix 5. Proof of Lemma 4}

As in Appendix 1 and Appendix 3, the IC constraint (18) must induce the manager to exert high effort in both periods and consists of three following conditions. The first condition is Utility(working/working) $\geq U$ tility (working/shirking), which reduces to:

$\pi_{L} \leq \pi_{H}-c_{W}^{0} /\left(\theta_{S}-\theta_{W}\right)$

where we use $\theta_{W} \beta_{L}+\left(1-\theta_{W}\right) \beta_{H}>0$ and assume $c_{S}^{0}=0$. The second condition,

Utility(working/working) $\geq U t i l i t y$ (shirking/working), is simplified to

$\left(\pi_{L}-R_{L}+\beta_{L}\left(\bar{\pi}_{W}-R^{L}-c^{L W}\right)\right)-g_{L} \leq\left(\pi_{H}-R_{H}+\beta_{H}\left(\bar{\pi}_{W}-R^{H}-c^{H W}\right)\right)-g_{H}$

$-c_{W}^{0} /\left(\theta_{S}-\theta_{W}\right)$

The third condition is Utility (working/working) $\geq$ Utility (shirking/shirking) and we will show that Utility(working/working) $\geq U$ Utility(shirking/working) $\geq$

Utility(shirking/shirking). Since the former inequality holds true by (68), it remains to prove that the latter inequality is also satisfied. Simplifying the latter inequality yields $\left[\left(\pi_{H}-\pi_{L}\right)\left(\theta_{S}-\theta_{W}\right)-\left(c_{W}^{0}-c_{S}^{0}\right)\right]\left[\theta_{S} \beta_{L}+\left(1-\theta_{S}\right) \beta_{H}\right]$, which is obvious by (68) and the condition $\left[\theta_{S} \beta_{L}+\left(1-\theta_{S}\right) \beta_{H}\right]>0$, hence the proof.

One can further show that the IC constraint (18) is a combination of condition (21) and the IC constraint (19). To prove that, we rearrange the IC constraint (18) and yield the following inequality

$\left(\pi_{H}-\pi_{L}\right)+\left[\left(-R_{H}-c_{H W}+\beta_{H}\left(\bar{\pi}_{W}-R^{H}-c^{H W}\right)\right)-\left(-R_{L}-c_{L W}+\beta_{L}\left(\bar{\pi}_{W}-R^{L}-c^{L W}\right)\right)\right] \geq c_{W}^{0} /\left(\theta_{S}-\theta_{W}\right)$

which is automatically satisfied, since $\left(\pi_{H}-\pi_{L}\right) \geq c_{W}^{0} /\left(\theta_{S}-\theta_{W}\right)$ by condition (21), and the second term in brackets is an arrangement of the IC constraint (19) and is nonnegative. 


\section{Appendix 6. Proof of Lemma 5 \& Proposition 3}

As in the proof of Proposition 2, the procedure involves three main steps. First, we formulate the Kuhn Tucker Lagrangian function and derive the first-order conditions. Second, solve for the Lagrangian parameters by analysing the first-order conditions and the complementary slackness conditions. Third, we consider the cases in which $\beta_{L}=0, \beta_{L}=1$ or $0<\beta_{L}<1$ and then show that only in the first case the model obtains an optimal contract.

First, Problem $(\mathrm{C})$ can be rewritten as follows:

$\operatorname{Max} f\left(\beta_{i}, R_{i}, R^{i}\right)=-F+\theta_{W}\left(R_{L}+\beta_{L}\left(R^{L}-F\right)\right)+\left(1-\theta_{W}\right)\left(R_{H}+\beta_{H}\left(R^{H}-F\right)\right)$

subject to

$$
\begin{aligned}
& R_{H}-R_{L}+\beta_{H} R^{H}-\beta_{L} R^{L}-\beta_{H}\left(\bar{\pi}_{W}-c^{H W}\right)+\beta_{L}\left(\bar{\pi}_{W}-c^{L W}\right)+c_{H W}-c_{L W} \leq 0 \\
& R_{L} \leq \pi_{L} \\
& R_{H} \leq \pi_{H} \\
& R_{L}+R^{L} \leq 2 \pi_{L} \\
& R_{H}+R^{H} \leq \pi_{H}+\pi_{L}
\end{aligned}
$$

under the condition $\pi_{H}-\pi_{L} \geq c_{W}^{0} /\left(\theta_{S}-\theta_{W}\right)$.

The Kuhn-Tucker Lagrangian function is:

Maximise $L=-F+\theta_{W} R_{L}+\theta_{W} \beta_{L}\left(R^{L}-F\right)+\left(1-\theta_{W}\right) R_{H}+\left(1-\theta_{W}\right) \beta_{H}\left(R^{H}-F\right)$

$$
\begin{aligned}
& -\lambda_{1}\left(R_{H}-R_{L}+\beta_{H} R^{H}-\beta_{L} R^{L}-\beta_{H}\left(\bar{\pi}_{W}-c^{H W}\right)+\beta_{L}\left(\bar{\pi}_{W}-c^{L W}\right)+c_{H W}-c_{L W}\right) \\
& -\lambda_{2}\left(R_{L}-\pi_{L}\right)-\lambda_{3}\left(R_{H}-\pi_{H}\right)-\lambda_{4}\left(R_{L}+R^{L}-2 \pi_{L}\right)-\lambda_{5}\left(R_{H}+R^{H}-\pi_{H}-\pi_{L}\right)
\end{aligned}
$$

where $\lambda_{i}(i=1 . .5)$ are non-negative Lagrangian parameters.

Second, assuming $\beta_{L}$ and $\beta_{H}$ are given, the first-order conditions are: 
$\partial L / \partial R_{L}=\theta_{W}+\left(1+g_{L}^{\prime}\right) \lambda_{1}-\lambda_{2}-\lambda_{4} \leq 0$

$\partial L / \partial R_{H}=\left(1-\theta_{W}\right)-\left(1+g_{H}^{\prime}\right) \lambda_{1}-\lambda_{3}-\lambda_{5} \leq 0$

$\partial L / \partial R^{L}=\theta_{W} \beta_{L}+\lambda_{1} \beta_{L}\left(1+g^{L^{\prime}}\right)-\lambda_{4} \leq 0$

$\partial L / \partial R^{H}=\left(1-\theta_{W}\right) \beta_{H}-\lambda_{1} \beta_{H}\left(1+g^{H^{\prime}}\right)-\lambda_{5} \leq 0$

$\partial L / \partial \lambda_{i} \geq 0$ where $i=1 . .5$

Further, there are also complementary slackness conditions. Since transfers are positive, the above conditions must be binding. Solving for $\lambda_{i}(i=2 . .5)$ w.r.t. $\lambda_{1}$

$$
\begin{aligned}
& \lambda_{2}=\left(1-\beta_{L}\right)\left(\theta_{W}+\left(1+g^{L^{\prime}}\right) \lambda_{1}\right)+\left(g_{L}^{\prime}-g^{L^{\prime}}\right) \lambda_{1} \\
& \lambda_{3}=\left(1-\beta_{H}\right)\left(1-\theta_{W}-\left(1+g^{H^{\prime}}\right) \lambda_{1}\right)-\left(g_{H}^{\prime}-g^{H^{\prime}}\right) \lambda_{1} \\
& \lambda_{4}=\beta_{L}\left(\theta_{W}+\left(1+g^{L^{\prime}}\right) \lambda_{1}\right) \\
& \lambda_{5}=\beta_{H}\left(1-\theta_{W}-\left(1+g^{H^{\prime}}\right) \lambda_{1}\right)
\end{aligned}
$$

where $\lambda_{1} \in R^{+}$.

Next, examine the following three cases: $\beta_{L}=0, \beta_{L}=1$ or $0<\beta_{L}<1$.

Case 1: $\beta_{L}=0$. When $\beta_{L}=0, \lambda_{2}=\theta_{W}+\left(1+g_{L}^{\prime}\right) \lambda_{1}>0$ and so due to complementary slackness, $R_{L}=\pi_{L}$. The maximisation problem becomes

$$
f=-F+\theta_{W} \pi_{L}+\left(1-\theta_{W}\right)\left(R_{H}+\beta_{H}\left(R^{H}-F\right)\right)
$$

Thus to maximise the objective function is to maximise $\left(R_{H}+\beta_{H}\left(R^{H}-F\right)\right)$.

Rearranging the IC constraint (70) yields the following

$$
R_{H}+g_{H}+\beta_{H}\left(R^{H}+g^{H}\right) \leq \beta_{H}\left(\bar{\pi}_{W}-c_{W}^{0}\right)+\left(\pi_{L}+g\left(\pi_{L}\right)\right)
$$

or

$$
R_{H}+g_{H}+\beta_{H}\left(R^{H}+g^{H}-F\right) \leq \beta_{H}\left(\bar{\pi}_{W}-c_{W}^{0}-F\right)+\left(\pi_{L}+g\left(\pi_{L}\right)\right)
$$


where $\left(R_{H}+\beta_{H}\left(R^{H}-F\right)\right)$ is maximised when this IC constraint binds and $\beta_{H}=1$ (under the assumption $\left(\bar{\pi}_{W}-c_{W}^{0}-F-g^{H}\right) \geq 0$ ). Since we have obtained $R_{H}+R^{H}=\left(\bar{\pi}_{W}-c_{W}^{0}\right)+\left(\pi_{L}+g\left(\pi_{L}\right)\right)-\left(g_{H}+g^{H}\right)$, the expression $\left(R_{H}+R^{H}\right)$ is maximised when the sum $\left(g_{H}+g^{H}\right)$ is minimised, hence the proof for Lemma 5 .

Further, the specification of the optimal contract depends on the concavity of function $g$. Consider the following two cases. First, if $g$ is convex, $\left(g_{H}+g^{H}\right)$ is minimised when $R_{H}=R^{H}$ and the optimal contract specifies

Contract (FC5): $\beta_{L}=0, \beta_{H}=1, R_{L}=\pi_{L}, R^{L} \leq \pi_{L}, R_{H}=R^{H}=R^{*}$ where $R^{*}+g\left(R^{*}\right)=0.5\left[\left(\bar{\pi}_{W}-c_{W}^{0}\right)+\pi_{L}+g\left(\pi_{L}\right)\right]$.

Contract (FC5) satisfies all the conditions of the Kuhn-Tucker theorem and the constraints of the model. The IR constraint is satisfied if and only if:

$\theta_{S}\left[\pi_{L}-R_{L}-c_{L S}+\beta_{L}\left(\bar{\pi}_{S}-R^{L}-c^{L S}\right)\right]+\left(1-\theta_{S}\right)\left[\pi_{H}-R_{H}-c_{H S}+\beta_{H}\left(\bar{\pi}_{S}-R^{H}-c^{H S}\right)\right] \geq 0$ or $\left(\pi_{H}-\pi_{L}\right)-\left[\left(\theta_{S}-\theta_{W}\right)\left(\pi_{H}-\pi_{L}\right)-c_{W}^{0}\right] \geq g\left(\pi_{L}\right) /\left(1-\theta_{S}\right)$.

The investor signs the contract if and only if the expected payoff is non-negative $f=-F+\theta_{W} \pi_{L}+\left(1-\theta_{W}\right)\left[\left(\bar{\pi}_{W}-c_{W}^{0}-F\right)+\left(\pi_{L}+g\left(\pi_{L}\right)\right)-\left(g\left(R^{*}\right)+g\left(R^{*}\right)\right)\right] \geq 0$, or $\quad \bar{\pi}_{W}-c_{W}^{0}-F+g\left(\pi_{L}\right)-2 g\left(R^{*}\right) \geq\left(F-\pi_{L}\right) /\left(1-\theta_{W}\right)$.

Second, if $g$ is concave, $R_{H}$ and $R^{H}$ must be set equal to the lower and upper bounds of the solution range in order to minimise $\left(g_{H}+g^{H}\right)$. Further in order to ensure $\lambda_{3} \geq 0$, it requires that $g_{H}^{\prime}<g^{H^{\prime}}$, which implies $R_{H}>R^{H}$ (because the function is increasing and concave). One optimal contract exists when $R_{H}$ is set equal to the upper bound, $\pi_{H}$, as follows: 
Contract (FC6): $\beta_{L}=0, \beta_{H}=1, R_{L}=\pi_{L}, R^{L} \leq \pi_{L}, R_{H}=\pi_{H}, R^{H}=R^{* *}$ where $R^{* *}+g\left(R^{* *}\right)=\left(\bar{\pi}_{W}-c_{W}^{0}\right)-\left(\pi_{H}-\pi_{L}\right)-\left(g\left(\pi_{H}\right)-g\left(\pi_{L}\right)\right)$.

Contract (FC6) satisfies all the conditions of the Kuhn-Tucker theorem and the constraints of the model. The IR constraint for the entrepreneur requires that $\theta_{S}\left[\pi_{L}-R_{L}-c_{L S}+\beta_{L}\left(\bar{\pi}_{S}-R^{L}-c^{L S}\right)\right]+\left(1-\theta_{S}\right)\left[\pi_{H}-R_{H}-c_{H S}+\beta_{H}\left(\bar{\pi}_{S}-R^{H}-c^{H S}\right)\right] \geq 0$ or $\left(\pi_{H}-\pi_{L}\right)-\left[\left(\theta_{S}-\theta_{W}\right)\left(\pi_{H}-\pi_{L}\right)-c_{W}^{0}\right] \geq g\left(\pi_{L}\right) /\left(1-\theta_{S}\right)$. The investor only signs contract (FC6) when $f=-F+\theta_{W} \pi_{L}+\left(1-\theta_{W}\right)\left[\left(\bar{\pi}_{W}-c_{W}^{0}-F\right)+\left(\pi_{L}+g\left(\pi_{L}\right)\right)-\left(g\left(\pi_{H}\right)+g\left(R^{* *}\right)\right)\right] \geq 0$, or
$\left[\bar{\pi}_{W}-c_{W}^{0}-F-\left(g\left(\pi_{H}\right)-g\left(\pi_{L}\right)\right)-g\left(R^{* *}\right)\right] \geq\left(F-\pi_{L}\right) /\left(1-\theta_{W}\right)$ A feasible contract exists when $R_{H}=\pi_{L}$, the lower limit:

Contract (FC7): $\beta_{L}=0, \beta_{H}=1, R_{L}=\pi_{L}, R_{H}=\pi_{L}, R^{H}=R^{* *}$ where $R^{* *}+g\left(R^{* *}\right)=\left(\bar{\pi}_{W}-c_{W}^{0}\right)$

However, contract (FC7) does not fully satisfy the Kuhn-Tucker theorem because while (72) and (74) are not binding, $\lambda_{3}$ and $\lambda_{5}$ cannot be equal to 0 simultaneously. Finally, we can follow the strategy in Appendix 4 and show that in the cases when $\beta_{L}=1$ or $0<\beta_{L}<1$, the contracts are suboptimal. Detailed proof can be found in the Supplementary Proof, which is available upon request. 